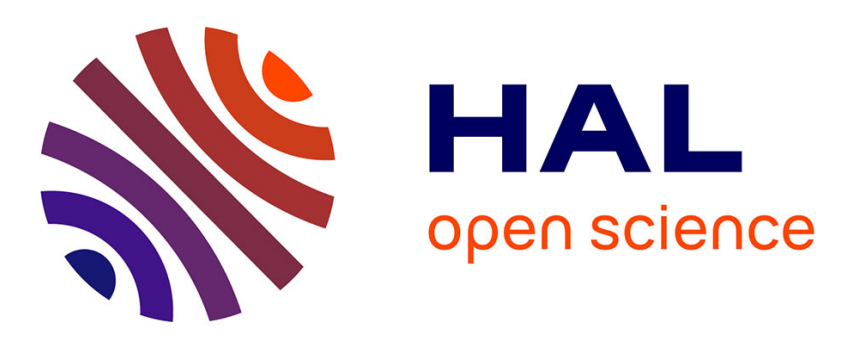

\title{
Decision evaluation process in end-of-life systems management
}

\author{
Yasmina Bouzarour-Amokrane, Ayeley Tchangani, François Pérès
}

\section{To cite this version:}

Yasmina Bouzarour-Amokrane, Ayeley Tchangani, François Pérès. Decision evaluation process in endof-life systems management. Journal of Manufacturing Systems, 2015, vol. 37 (n 3), pp. 715-728. 10.1016/j.jmsy.2015.03.007 . hal-01308899

\section{HAL Id: hal-01308899 \\ https://hal.science/hal-01308899}

Submitted on 28 Apr 2016

HAL is a multi-disciplinary open access archive for the deposit and dissemination of scientific research documents, whether they are published or not. The documents may come from teaching and research institutions in France or abroad, or from public or private research centers.
L'archive ouverte pluridisciplinaire HAL, est destinée au dépôt et à la diffusion de documents scientifiques de niveau recherche, publiés ou non, émanant des établissements d'enseignement et de recherche français ou étrangers, des laboratoires publics ou privés. 


\section{Open Archive Toulouse Archive Ouverte (OATAO)}

OATAO is an open access repository that collects the work of Toulouse researchers and makes it freely available over the web where possible.

This is an author-deposited version published in: http://oatao.univ-toulouse.fr/ Eprints ID: 15534

To link to this article: DOI:10.1016/j.jmsy.2015.03.007

http://dx.doi.org/10.1016/j.jmsy.2015.03.007

\section{To cite this version:}

Bouzarour-Amokrane, Yasmina and Tchangani, Ayeley and Pérès, François Decision evaluation process in end-of-life systems management. (2015) Journal of Manufacturing Systems, vol. 37. pp. 715-728. ISSN 0278-6125 
Technical Paper

\title{
Decision evaluation process in end-of-life systems management ${ }^{\text {is }}$
}

\author{
Yasmina Bouzarour-Amokrane $^{\mathrm{a}}$, Ayeley Tchangani ${ }^{\mathrm{b}, *}$, François Peres $^{\mathrm{a}}$ \\ a Universite De Toulouse/INPT/LGP, 47, Avenue d'Azereix, BP 1629, 65016 Tarbes Cedex, France \\ ${ }^{\mathrm{b}}$ Université de Toulouse/IUT de Tarbes/LGP, 1, rue Lauréamont, 65016 Tarbes Cedex, France
}

Keywords:

End-of-life product management

Reverse logistics

Withdrawal plan

BOCR analysis

Satisficing game

\begin{abstract}
A B S T R A C T
In manufacturing sectors, firms are paying an increasing attention to sustainability concept with regard to their end-of-life products in order to respect environmental norms and satisfy the consumer sensitivity. This practise allows creating value by reintroducing dismantling and recovering parts and/or materials of end-of-life products into manufacturing process, or into maintenance process. Thus, deconstruction processes are developed in order to examine all activities addressing the end of life (EOL) systems to ensure its disposal according to environmental constraints when seeking an economic optimum. In this context, one of the first tasks to perform is to repatriate the EOL systems at lowest cost considering geographical optimization of treatment centers. Considering this point, the present paper proposes an evaluation and optimization approach for the withdrawal location process in the field of aircraft dismantling. Given the multitude and heterogeneity of characteristics to be taken into account, we propose to consider dismantling site location problem as multi-criteria/multi-objectives decision making problem and solve it using a new AHP-BOCR approach based on qualitative and quantitative evaluations. A bipolar structuring framework is considered to distinguish positive and negative aspects in the elicitation/evaluation process to avoid compensation and satisficing game theory is used as suitable mathematical tool for recommendation process. An experimental study is carried out to show the usefulness of the
\end{abstract}

\section{Introduction}

Firms are increasingly interested in recovering used products due in particular to growing environmental awareness of population and increasing customer expectations of enterprises to dispose of manufactured products safely [1]. Considered as the best way for recovering some categories of end-of-life products [2,3], the EOL management becoming pervasive in socio-economic life, in order to consider questions dealing with the transport, reuse, refurbishment, recycling, disposal, secure storage, valorization, or, scrapped of EOL product $[4,5]$. These activities are included in the deconstruction process [6] which includes services of product returning, recycling, material substitution, reuse of materials, waste disposal, refurbishing, repair, and remanufacturing [7].

The deconstruction process is developed as part of the reverse logistics which discusses first, the planning process establishment to implement and control raw material flows, current inventory,

\footnotetext{
Preliminary version of this paper was presented at IFAC_MIM 2013 as a communication.

* Corresponding author. Tel.: +33 05624442 53; fax: +33 0562444219 .

E-mail addresses: yasmina bouzarour@enit fr (Y. Bouzarour-Amokrane) ayeley.tchangani@enit.fr (A. Tchangani), francois.peres@enit.fr (F. Peres).
}

finished goods from the point of use to the point of recovery. Reverse logistics also discusses the selection of proper disposal site and the optimization of the dismantling systems in order to reduce the negative impact of EOL products on the environment and to increase benefits of manufacturers thanks to recycling and recovery operations.

In the aerospace sector, increasing number of end-of-life planes requires to pay more attention to the elimination phase because EOL aircrafts contain valuable components and parts that can be reused and reintroduced in the aftermarket [8]. Moreover, the older fleet management and aircraft scrapping must face legislative pressure in terms of environmental protection laws and economic benefits [5] generated by policy of sustainable environment. These aspects are considered as critical factors in measuring the contribution of a firm to sustainable development. Thus, environmental, economic and social factors can be considered in reverse logistics to evaluate the efficiency of improvement actions. For example, economic factors can provide information on the benefits of adopting reverse logistics by manufacturers. Where cost saving and improving the corporate image allow to gain competitive advantage and to increase the environmental performance [9-12].

Among the issues addressed by the reverse logistics, the selection of proper disposal sites consists in aerospace sector to choose a withdrawal plan for the dismantling EOL aircraft. This issue 
requires optimizing some preference indicators such as, logistic costs, environmental effects, job creations, or economic enhancement. The withdrawal design phase allows to ensure geographical deployment reducing, long distance of EOL systems repatriation to the dismantling sites and limiting their storage needs or their processing capacity. This phase may take into account various parameters as: the complexity of the transport, the depth of disassembly (which products will be recycled?) and the sequencing of operations according to sustainable development (how to get the products while minimizing the time and cost of deconstruction, and maximizing the income generated by the products of the deconstruction?) [13]. An evaluation phase must then be realized to choose the best alternative among different existing deconstruction places. In fact, several sites can be candidates for the deconstruction operations which lead to many solutions in terms of logistics. In this context, the scrapped aircraft withdrawal plan location problem is considered in this paper. A new structured approach is proposed to resolve decision problem of the scrapped aircraft withdrawal plan location considering a new flexible bipolar context. A bipolar way is proposed to consider positive and negative aspects distinctly in order to identify the best alternative or the most satisficing one. The potential interaction of decision elements and the impact of human behavior on the final decision are taken into account. Given the large volume of data involved in solving the scrapped aircraft withdrawal plan location problem, this paper proposes to resolve it by using a multi-criteria/multi-objective decision approach based on AHP method which offers a robust hierarchical structure. The AHP process is adjusted to meet the needs and to minimize complications. BOCR analysis built upon the bipolar notion of supporting and rejecting that characterized relationships between attributes and objectives is demonstrating its power as a structuring tool for decision analysis, see for instance [65-69] for some modeling methods and applications based on this notion. The BOCR analysis considering benefit, opportunity, cost and risk factors is associated to AHP method in order to consider uncertainty aspect in adequate withdrawal plan identification. This approach allows distributing the data across four distinct factors thus forming less voluminous clusters reducing the number of pairwise comparison at the operational level. The potential interactions between problem characteristics are considered using Choquet integral. The proposed model allows alternatives to be characterized by heterogeneous criteria and manage incomparability between alternatives in terms of Pareto-equilibria using satisficing game theory in recommendation phase where a final selection is given according to positive and negative contribution.

\subsection{Literature review of facility location problems}

The facility location framework can consider different contexts involving multiproduct and multistage reverse logistics network problem for the return products [14], evaluating green supply chain alternatives $[15,16]$, recovery planning like the determination of the disassembly level [17], or the elaboration of catalog distributors to reduce costs from returns processing [18]. The facility location problems including remanufacturing are frequently encountered in the literature and solved using several approaches going from optimization to multicriteria evaluation. For example, in [19], authors used p-median method to calculate the minimum weighted distance from $\mathrm{p}$ manufacturing/remanufacturing facilities to $n$ demand locations considering the minimum efficient scale for environmental and economic performance. In [20], authors proposes a conceptual framework, an analytical model, and a three-stage algorithmic solution based on p-median approach. The objective was to determine the optimal number and location of receiving canters and the correct financial incentive in order to stimulate collection of used or unrecoverable products to a required degree. In order to locate recycling centers and to assign collection depots to those centers, authors in [21] propose 2-stage location set covering problem-p-median integrated model that obtains exact solutions using heuristic algorithms on the basis of set operations. The Mixed integer programming model [22-24] is another optimization approach used to capture, for example, component commonality among different products to have the flexibility to incorporate all plausible means in tackling product returns using a multi-commodity formulation and use a reverse bill of materials [25]. In some facility location problems, fuzzy context is considered [26-28] to take into account risk which influences the supply chain design and management and which can be related to uncertainty embedded in the model parameters (which affects the problem of balancing supply and demand) and/or, natural disasters, strikes and economic disruptions, or terroristic acts. The optimization methods offer complex technical resolution leading to a final 'optimal' solution characterizing the instruction given by the analyst once the resolution is complete. However, these methods are not always applicable and flexible for complex problems with a large volume of data. For p-median method for example, it is difficult to solve the instances of very large sizes and the associated classical linear relaxation to this problem. For mixed integer programming model using integer variables make an optimization problem non-convex and therefore far more difficult to solve. Memory and solution time may rise exponentially as more integer variables are added.

The multicriteria context is proposed as an alternative in some studies with fuzzy TOPSIS method [29], AHP approach [30,31], ELECTRE III method [32], or fuzzy compromise programming [33] to deal with the vagueness of human judgments and determine marginal utility function for each criteria to consider scaling and subjective weighting issues. It is argued that the selection of a facility location is a multi-criteria decision-making problem including both quantitative and qualitative criteria. This supports the use of multicriteria methods as those given above. However, some methods although easy to implement, can be restrictive, depending on the problem considered. For example, TOPSIS method based on ideal and non-ideal notion has the disadvantage of only considering cardinal criteria where preferences are fixed a priori and method provides the best action among the poor if all the alternatives are not satisfactory. For the AHP method based on hierarchical structure and linguistic scale, a large number of decision elements can increase the number of pairwise comparisons and a rank reversal problem can occur where two actions can view their order priority reversed after adding or deleting one or several actions. For outranking ELECTRE III method using a veto threshold, the complexity lies in the large number of technical parameters and in the interpretation which may be difficult. More generally, complex decision problem considering a multitude of objectives, a variety of conflicting and often heterogeneous criteria and multiple actors with different opinions and personalities, in a potentially uncertain environment make multicriteria modeling necessary to consider simultaneously all these aspects. Compromises are then required to achieve a response. However, the multicriteria modeling proposed in literature considers generally that elicitation of criteria is independent of alternatives and objectives, which is not always true in practice. On the other hand, aggregation methods are used to represent alternative with a unique value. This compensatory approach does not distinguish between the positive and negative aspects that alternatives present regarding objectives.

The remainder of this paper is organized as follows: Section 2 introduces the characteristics of deconstruction processes. Section 3 addresses the structured framework method for analysis development starting with an introduction of proposed AHP-BOCR approach and, detailed then the steps of aggregation phase and the basis of the satisficing game theory used on the recommendation phase. Section 4 provides an example of application. 
Section 5 concludes the article and discusses some perspectives and guidelines for future works.

\section{Deconstruction process characteristics}

Deconstruction process is a system that involves all activities addressing the EOL system to ensure its disposal according to environmental constraints when seeking an economic optimum. It consists of a set of physical, human, information and energy entities. Hardware resources can be structured hierarchically following the decomposition of the main system subassemblies and individual components [34]. The development and implementation of a deconstruction system is a complex task that requires the realization of a deconstruction project. In general, a deconstruction project aims to define the management of EOL systems in order to achieve objectives such as the valuation of their components, proposition of regenerative active products, the mastery of operations for ensuring the safety, disassembly and dismantling, as well as the separation of hazardous components to ensure the safety of the environment and traceability of reuse parts from deconstruction.

The objectives of a deconstruction project are mainly expressed in terms of operations control for ensuring the safety, disassembly and dismantling, recovery of materials (formulated as recovery rates generally ranging from $70 \%$ to $95 \%$ ) and traceability of reuse of parts from decommissioning. To achieve these objectives, three phases can be distinguished in a deconstruction process [34,37] (see Fig. 1):

1. Reverse logistics phase: the first step deals with reverse logistics activities; the EOL system is out of service, stored, cleaned and, depending on the type of system, decontaminated and secured until its management. The objective here is to repatriate the EOL systems at lowest cost considering geographical optimization of treatment centers, thinking about parking places, or transport modes.

2. Dismantling phase: when the EOL system arrives to the selected site, dismantling activities can be implemented. First, parts which can be reused are recovered and sent in a repair shop before being recycled. The Dislocation is then realized by separating the system components according to the nature of materials, their formatting for handling (cutting, batch training). The dislocation can also deals with draining the system and the removal of pollutants and hazardous materials. The goal is to recover the components (such as engine, landing gear, equipment) that can be potentially reused on one hand and, in case it is not possible or not economically worthy, to extract reusable materials (such as aluminum, alloys, plastics). This step allows the production of valuable products representing an added value in the process.

3. Valorization phase: where treatment of EOL system part or material is realized to give them a value. There are generally four types of recovery.

- functional recycling: reinstate the products resulting from the deconstruction;

- material recycling: reusing the material components of the EOL system;

- energy recovery: incinerating of non-recyclable products obtained from deconstruction to produce energy;

- packaging and storage of hazardous products and products that cannot be valued in environmental friendly conditions.

Our work is a part of the implementation of the first phase of deconstruction process. The objective is to ensure optimal geographical deployment of deconstruction site with lower cost considering, geographic optimization of treatment centers, reflection on parking site, transport modes, and traffic pattern.

The determination of deconstruction site is a complex decision problem requiring to consider contradictory objectives usually related to economic, ecological and social notions. The first resolution phase consists to form a committee of experts and to define parameters and characteristics of the problem. Considering fixed objectives and involved aspects in the problem selection, the identification of potential sites is based on parameters such as; the logistics chain operations, resources needed to carry operations, possible transportation methods, the storage capacity, the economic parameters (such as the cost and profit generated by each potential site), social parameters (such as the employment creation) and environmental parameters (such as the level of pollution generated). To evaluate characteristics of potential withdrawal sites, several criteria related to economic profit, valorization

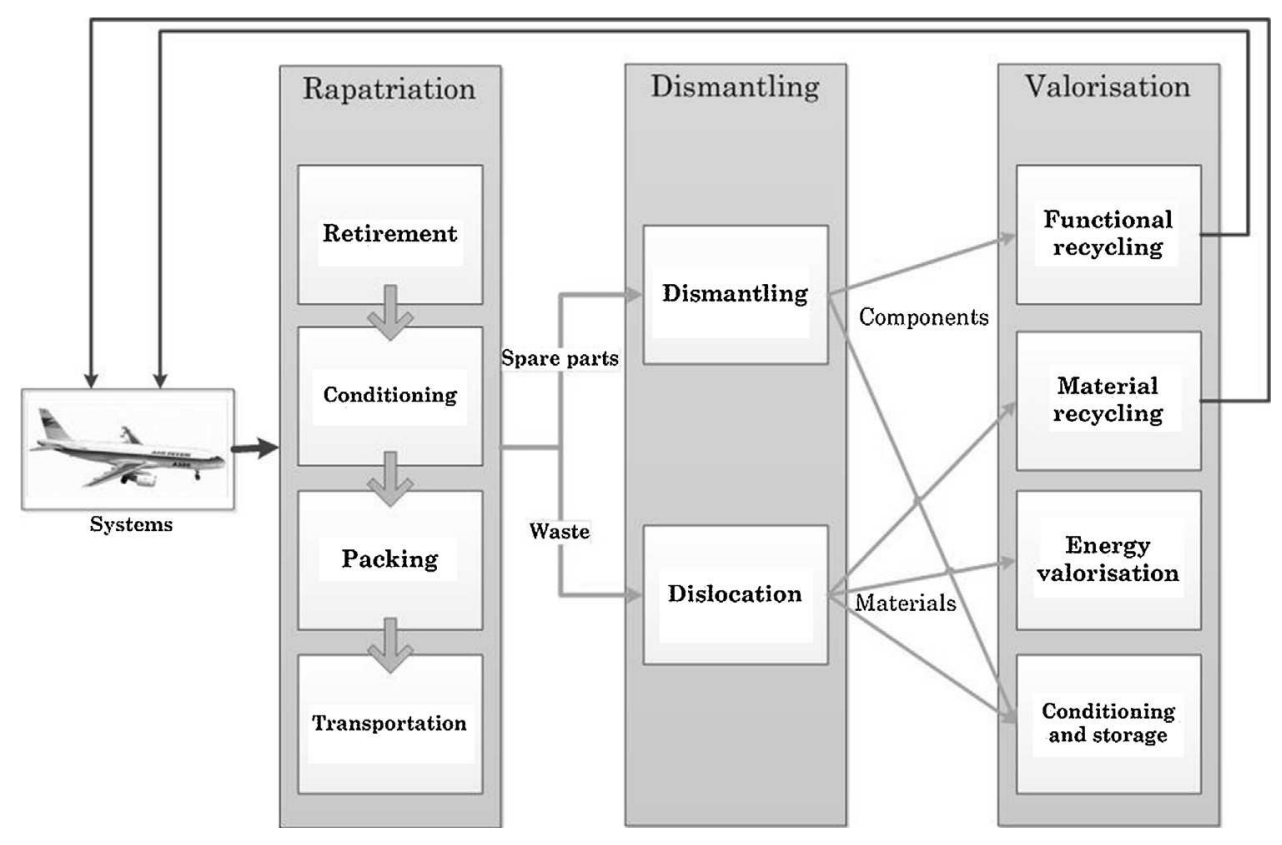

Fig. 1. Disassembly process representation [35]. 
rate, and ecological balance have to be taken into account [13]. Based on literature reviews and practical experiences, the committee of experts define a set of indicators such as those suggested below.

Economic indicators: related to costs and revenues generated by the development of a deconstruction site. Cost indicators include logistic costs (such as transport and conditioning), production cost (deconstruction cost), management costs and administrative cost. Revenues indicators imply generally valorization revenues related to the expected sales forecasts, quantities of coming products and monetary values. Other revenues related to the potential benefits with the corresponding incomes as components sale and saving taxes can be considered. These indicators can be detailed in quantifiable criteria for evaluation. In logistic costs for example, the evaluation of transport cost can consider distance and cost $/ \mathrm{km}$ criteria including fuel costs, transportation maintenance, tolls, transportation taxes (fixed costs), and rental cost-related to resources, travel insurance, payroll service providers - cost of userelated to depreciation of machinery or tools - travel time and resource efficiency (variables costs). For conditioning costs, several criteria can be considered; the ratio of qualified workforce work can informs on the degree of work complexity and the labor costs, cost/h including energy as fuel, gas and electricity, rental cost including tariffs for incurred services and tools for conditioning (shears or cranes).

Environmental indicators: can be divided into qualitative and quantitative economic and non-economic indicators focusing on the measurement of physical data, i.e. emissions, waste, energy and transportation [36], or residual waste and energy [24]. In this paper, to assess the impact of the dismantling project on individuals and the biotic and abiotic environment according to environmental regulations, the pollution indicators are considered in the evaluation process. The revalorization and treatment indicators such as recycling and confinement are proposed to estimate benefits of dismantling project.

The pollution indicators consider some criteria such as, pollution sources (tanks, vessels, piping, storage areas and warehousing drums, cans, bags - chronic or accidental spills, or waste buried contaminated soil), transfer mode of pollution (possible vectors are water surfaces, groundwater, air -spread by the wind) and target threatened or affected (human beings, fauna and flora). The impact on humans can be visual (disruption duration, number of affected persons), respiratory (level of air quality, number of affected persons), or acoustic (average decibel, number of affected persons). The impact on environment can be estimated considering quantity of waste and its impact (on air quality, pollution of water sources, or soil pollution), or transport mode (fuels consumption).

The revalorization and treatment indicators can be evaluated considering recycling criteria (\% recycled materials, \% reused materials), power generation and containment of hazardous materials, number of accidents per year, average severity of accidents, number of employees involved, or level of stakeholder satisfaction.

Social indicators: proposed to characterize the social performance of the project considering positive (employment) and negative impact (perturbations or accidents) of the project on the society. Criteria as visual, acoustic, respiratory perturbations and accidents can be considered for negative impact where positive impact can be estimated considering satisfaction level of stakeholders and number of hired employees. The complete list of proposed criteria for dismantling lactation problem is summarized in the last section.

The evaluation committee can be composed by several actors participating in the definition of dismantling process. The most important stakeholders may be represented by the following entities [13].
Operating companies: they have exploitation rights of the EOF aircrafts without necessarily being their owners. The operating company is the starting point of the dismantling process.

The owner company: it has the aircraft and it is responsible for the selection of deconstruction site after alternatives evaluation.

Dismantling company: the company that deals with deconstruction. It deconstructs the aircraft in accordance with the owner. The Negotiation parameters include costs, dates, or profits.

Other actors: transport companies, cleaning, insurance, government organizations and/or NGOs.

Modeling a deconstruction site location problem must integrate all of the above elements and provide support for the implementation of an optimization method. Indeed, for large systems with many recovery trajectories (alternatives), the data evaluates potential solutions can be very large and automated search for an ideal solution can be necessary. To find the withdrawal plan that meets the fixed objectives without violating the regulations, the following section propose to consider the dismantling site location problem as a multicriteria decision problem and resolve it using bipolar approach based on Analytic Hierarchy Process and BOCR analysis.

\section{Structured framework for analysis}

Considering dismantling sites as potential alternatives noted $A=\left\{a_{1}, a_{2}, \ldots, a_{n}\right\}$, the evaluation method must quantify the capacity of each site to meet the objectives of decision makers noted $O=\left\{o_{1}, o_{2}, \ldots, o_{q}\right\}$. To resolve multicriteria decision problem, the literature presents generally alternatives by a common set of criteria for all objectives. However, in practice there are cases where the criteria are dependent on alternatives and/or objectives. The proposed approach offers the possibility of conducting elicitation of criteria for each pair (alternative, objective) in order to quantify alternative potential to achieve the objectives. A set of criteria for $\left(o_{l}, a_{i}\right)$ is noted $C^{o_{l}}\left(a_{i}\right)=\left\{c_{1}^{O_{I}}, c_{2}^{O_{I}}, \ldots, c_{m}^{O_{I}}\right\}$. In decision problems, characteristics of alternatives may be detailed in several levels through detailed criteria going form general to operational level. Once quantifiable criteria evaluated, the opposite path is taken by aggregating subsets of each level in order to quantify potential of alternatives (see Fig. 2). The formulation of criteria hierarchically, has become the main feature of the analytic hierarchy process (AHP) developed by Saaty [37]. This hierarchy of criteria allows the analyst to structure the decision problem providing users a better understanding and allowing them to focus on allocation of weights to the criteria and sub-criteria. We propose in the next section to use AHP process in modeling and evaluation phases of proposed approach. The evaluation results at each level are assumed normalized in the range $[0,1]$ in order to maintain a same order of magnitude for evaluations. It is assumed that alternative performance can be assessed through a set of indicators noted $I^{O} l\left(a_{i}\right)$ to estimate the degree of achievement of objective $o_{l}$ considering alternative $a_{i}$ (Eq. (1)).

$I^{o_{l}}\left(a_{i}\right)=\varphi^{o_{l}}\left(c^{o_{l}}\left(a_{i}\right)\right)$

where $\varphi^{o_{l}}$ represents an aggregation measure of correspondent component.

The proposed approach considers a social choice problem where decision makers seek to obtain a final decision in collective way. In this case, based on the proposed framework by the analyst, the role of stakeholders is to elicit commonly the problem characteristics in the elicitation phase and then evaluate them depending on their discipline, knowledge and experience. The selection processes of criteria are structured hierarchically where global criteria are detailed until operational level. The number of considered criteria is not limited in this approach. However, it is clear that a large 


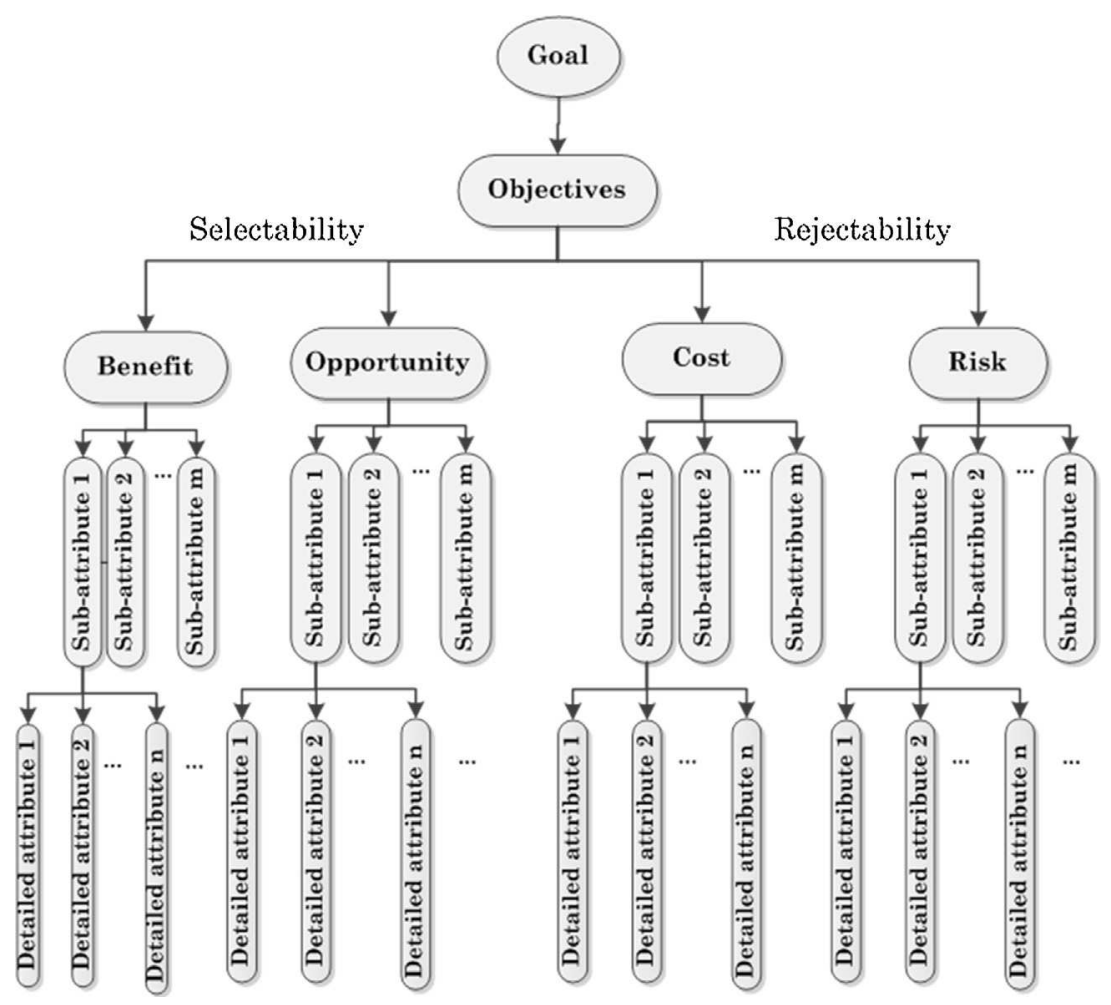

Fig. 2. Hierarchical structuration of criteria.

number of parameters would make the process more complicated and lengthy.

The stages of the corresponding decision making problem are as follows:

1. Actors select objectives and indicators to measure their degree of achievement.

2. Potential alternatives are identified by actors.

3. For each pair (objective, alternative), actors can determine a set of criteria that permit the evaluation of an alternative with regard to an objective.

4. Alternatives are evaluated with regard to objectives for recommendations.

The aim of this paper is to develop a new AHP-BOCR approach based on qualitative and quantitative evaluations to structure and solve dismantling site location problem. The analytic hierarchy process (AHP) proposed by Saaty [38] allows solving complex and unstructured decision problems from a pairwise comparison of relative criteria under a hierarchical structure. To evaluate the feasibility of dismantling sites installation, a BOCR analysis (see for instance [65]), is associated to AHP method to analyze alternatives based on Benefit (B), Opportunity (O), Cost (C) and Risk (R) aspects simultaneously. In the proposed bipolar approach, the positive criteria of benefit (certain) and opportunity (uncertain) and the negative criteria of cost (certain) and risk (uncertain) are synthetizing distinctively through the selectability and rejectability notions in order to rank alternatives considering positive and negative impacts respectively, before the recommendations. We define positive/negative criteria in terms of supporting/rejecting objective achievement as criteria positively/negatively correlated with the variation of considered objective. Elicitation of positive/negative criteria in BOCR framework can be done by answering questions as "what are the certain/uncertain characteristics that represent a benefit/opportunity (cost/risk) in using the alternative ' $a_{i}$ ' to achieve objective ' $o_{l}$ ??". Two distinct groups are identified:

- the set of criteria supporting the achievement of objective ' ${ }_{l}$ ' noted $C_{s}^{o_{l}}\left(a_{i}\right)$, where $C_{s}^{o_{l}}\left(a_{i}\right)=C_{b}^{o_{l}}\left(a_{i}\right) \cup C_{o}^{o_{l}}\left(a_{i}\right)$. This set includes benefits criteria noted $C_{b}^{O_{l}}\left(a_{i}\right)$ and opportunity criteria noted $C_{o}^{O_{l}}\left(a_{i}\right)$.

- the set of criteria rejecting the achievement of objective ' $o_{l}$ ' noted $C_{o}^{o_{l}}\left(a_{i}\right)$ where $C_{r}^{o_{l}}\left(a_{i}\right)=C_{c}^{O_{l}}\left(a_{i}\right) \cup C_{r}^{o_{l}}\left(a_{i}\right)$. This set includes cost criteria noted $C_{c}^{o l}\left(a_{i}\right)$ and risk criteria noted $C_{r}^{o l}\left(a_{i}\right)$.

The AHP-BOCR evaluation method and the recommendation phase are developed in the next section.

\subsection{AHP-BOCR evaluation approach}

First introduced by Saaty in the 70s, the analytic hierarchy process has become one of the most commonly used methods in multicriteria decision literature [38]. The principle of the AHP method is to decompose a decision problem into different elements grouped in clusters, in a linear hierarchy starting from general to particular. Criteria are detailed until reaching operational level that allows alternatives evaluation [39]. Saaty also proposed a BOCR analysis method to let decision makers dealing with benefits, opportunities, costs, and risks [40-42]. The degree of objective achievement may be described by these four factors [43] where each one is represented by a set of criteria detailed in sub hierarchy going from general to operational level. Considering bipolar relationships, strength assessment using AHP-BOCR analysis is obtained by distinguishing positive (selectability notion) and negative (rejectability notion) factors. Pairwise comparison is carried out to quantify the relative importance of each element with respect to the objective achievement (Fig. 2).

The relative importance is obtained for each element by a pairwise comparison with respect to an element of the upper hierarchy 
Table 1

AHP scale.

\begin{tabular}{ll}
\hline Qualitative scale & Numerical values \\
\hline Equally important & 1 \\
Moderately more important & 3 \\
Strongly more important & 5 \\
Very strongly more important & 7 \\
Extremely more important & 9 \\
Intermediate scales (compromise) & $2,4,6,8$ \\
\hline
\end{tabular}

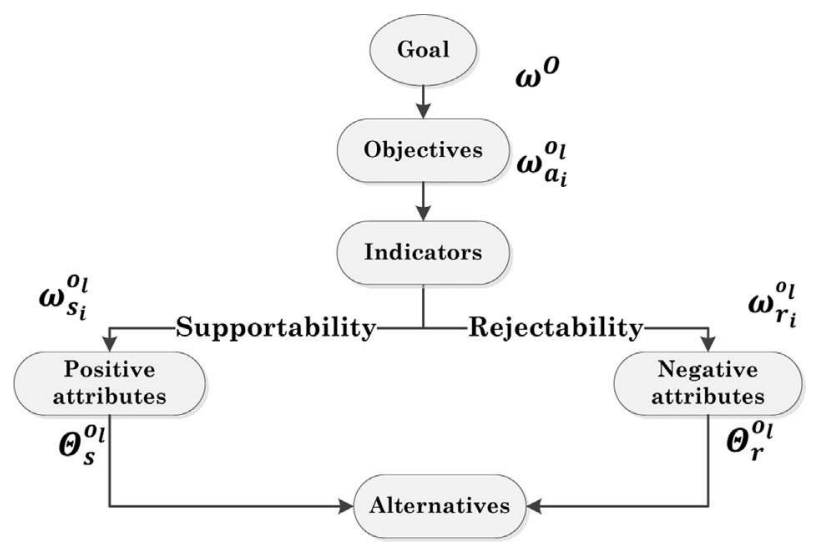

Fig. 3. Parameters of proposed AHP-BOCR approach

level using a ratio scale such as an AHP scale showed in Table 1. Unlike interval scales [44], the ratio scale does not require any unit. The evaluation can be made from a verbal judgment representing a relative value or same unit quantity fraction. This approach has been welcomed by psychologists who consider easier and more accurate to express their opinion by considering only two elements instead of a set of elements simultaneously [45].

In the evaluation phase, a set of parameters must be quantified by decision makers (Fig. 3) to determine the performance of each alternative. The detailed evaluation of these parameters is discussed below.

\section{Step 1. Identification of weight parameters}

The evaluation of the decision problem by the AHP procedure starts with the assessment of the objective importance considering the overall goal [39]. A pairwise comparison of the set of objectives is achieved by answering questions such "how important is objective ' $o_{k}$ ' compared to the objective ' $0 l$ ' with regard to the overall decision goal noted $O$." The AHP scale given in Table 1 is used to obtain a pairwise comparison matrix noted $\left(\Omega^{O}\left(l, l^{\prime}\right)\right)_{q \times q}$ (see below), where $\Omega^{O}\left(l, l^{\prime}\right)$ corresponds to relative importance of the objective $o_{l}$ compared to the objective $o_{l^{\prime}}$.

$$
\begin{aligned}
& \begin{array}{llll}
o_{1} & o_{2} & \ldots & o_{q}
\end{array} \\
& \Omega^{O}=o_{2}^{o_{1}} \begin{array}{cccc}
1 & \Omega_{1,2}^{k, O} & \ldots & \Omega_{1, q}^{k, O} \\
\vdots & o_{q}
\end{array}\left(\begin{array}{cccc}
\Omega_{2,1}^{k, O} & \ldots & \Omega_{l, l^{\prime}}^{k, O} & \ldots \\
\vdots & \Omega_{l^{\prime}, l}^{k, O}=1 / \Omega_{l^{\prime}, l}^{k, O} & \ddots & \vdots \\
\Omega_{q, 1}^{k, O} & \ldots & \ldots & 1
\end{array}\right)
\end{aligned}
$$

This matrix must be consistent and satisficing transitivity condition on all comparisons. This means that the matrix $\Omega^{O}$ must satisfy the following conditions $\Omega^{O}(l, l)=1, \Omega^{O}\left(l, l^{\prime}\right)=1 / \Omega^{O}\left(l^{\prime}, l\right)$ and $\Omega^{O}(l$, $\left.l^{\prime}\right)=\Omega^{O}\left(l, l^{\prime \prime}\right) \cdot \Omega^{O}\left(l^{\prime \prime}, l^{\prime}\right)$ (for more details see $[46,45]$ ). If the matrix is perfectly consistent, the condition of transitivity $\Omega^{O}\left(l, l^{\prime}\right)=\Omega^{O}(l$, $\left.l^{\prime \prime}\right) \cdot \Omega^{O}\left(l^{\prime}, l^{\prime}\right)$ is satisfied on all comparisons. To avoid checking the consistency after an arbitrary matrix construction, we propose a straightforward approach that leads to a consistent matrix [39]:

- select a pivot objective noted $o_{p}$

- compare other objectives to this pivot to obtain $\operatorname{scores} v(l, p)$ (from Table 1 ) for all other objectives $j \neq p$

- generate the matrix $\Omega^{O}$ with;

$$
\begin{aligned}
\Omega^{O}(l, p) & =v(l, p), \Omega^{O}(p, l)=1 / v(l, p), \Omega^{O}\left(l, l^{\prime \prime}\right) \\
& =\Omega^{O}(l, p) \Omega^{O}\left(p, l^{\prime}\right)=\Omega^{O}(l, p) / \Omega^{O}\left(l^{\prime \prime}, p\right)
\end{aligned}
$$

The relative comparison vector ' $\omega^{0}$ ' is calculated using Eq. (3).

$\omega^{O}\left(o_{l}\right)=\frac{1}{q} \sum_{l^{\prime \prime}=1}^{q}\left(\frac{\Omega^{O}\left(l, l^{\prime \prime}\right)}{\sum_{q}^{i=1} \Omega^{O}\left(i, l^{\prime \prime}\right)}\right)$

The relative importance of indicators $I^{0} l\left(a_{i}\right)$ given an objective $o_{l}, \forall o_{l} \in O$, is then evaluated by the way of a pairwise comparison. For each alternative $a_{i}$, the relative importance vector of indicators $I^{o_{l}}\left(a_{i}\right)$ for objective $o_{l}$ is noted $\omega_{i}^{o_{l}}$. This vector is obtained from a consistent matrix noted $\Omega_{i}^{o_{l}}$ (Eq. (3)). In BOCR framework, the degree of relative importance of criteria with respect to the objectives is noted $\omega_{\times}^{O_{l}}$ where $\omega_{\times}^{O_{l}}\left(c_{j}\right)$ represents the relative importance of $c_{j} \in C_{\times}^{o_{l}}\left(a_{i}\right)$ for each category $\times=b, o, c, r$. The vector $\omega_{\times}^{o_{l}}$ can be obtained in the same way as vectors $\omega_{i}^{o}$ and $\omega^{O}$.

\section{Step 2. Alternative evaluation}

The evaluation matrix of the alternative noted $\Theta_{x}^{o_{l}}$ considering different sub-sets of criteria $C_{x}^{o_{l}}(\times=b, o, c, r)$ can be obtained in two ways:

For a given criteria, if the evaluation of the alternative is quantitative with $c_{j}^{o_{l}}\left(a_{i}\right)$ the performance of alternative $a_{i}$ with regard to $c_{j}^{o_{l}}$, then the pairwise comparison matrix $\Omega_{\times}^{c_{j}^{o_{l}}}$ for each category $x=b, o, c, r$ is obtained through Eq. (4).

$\Omega_{\times}^{c_{j}^{o_{l} l}}\left(a_{i}, a_{i^{\prime}}\right)=c_{j}^{o_{l}}\left(a_{i}\right) / c_{j}^{o_{l}}\left(a_{i^{\prime}}\right)$

Otherwise, the pairwise comparison matrix $\Omega_{\times}^{c_{j}^{o l}}$ for each category $x=b, o, c, r$ can be obtained using AHP method by answering questions like "what is the performance of the alternative $a_{i}$ in comparison to alternative $a_{i^{\prime}}$ considering the criteria $C_{j}^{o_{l}}$ ?". The values of the evaluation matrices $\Theta_{\times}^{o_{l}}$ are calculated from the Eq. (5) [39].

$\Theta_{\times}^{o_{l}}\left(a_{i}, c_{j}^{o_{l}}\right)=\frac{1}{n} \sum_{i^{\prime}=1}^{n}\left(\frac{\Omega_{\times}^{c_{\times}^{o_{l}}}\left(a_{i}, a_{i^{\prime}}\right)}{\sum_{i^{\prime \prime}} \Omega_{\times}^{c_{j}^{o_{l}}}\left(a_{i^{\prime \prime}}, a_{i^{\prime}}\right)}\right)$

Once the AHP procedure has been carried out considering BOCR analysis, the performance evaluation of alternatives is represented by $b, o, c, r$ factors obtained after aggregation. The proposed aggregation phase is developed in the next part.

\subsection{Aggregation phase}

The aggregation concept is a common feature for all multicriteria decision problems evaluation procedures such as; the theory of multi-criteria utility (MAUT) and outranking methods. In MAUT procedure, one-dimensional utility functions are aggregated into an overall utility function by combining all the criteria, whereas in outranking methods (such as ELECTRE), preference relations are aggregated by pair alternatives (see $[47,48]$ ). To aggregate a set of data and represent them by a single value, the most used aggregation method is the average weighted arithmetic [49-51]. This method has the drawback of ignoring the interaction between 
the aggregate components, as the synergy, redundancy or independence. To remedy this, fuzzy integrals were then put up. Considering positive and negative aspects distinctly in proposed approach promotes synergistic relationships between the criteria of each cluster. In this context, we propose the use of Choquet integral $[52,47]$ as aggregation tool to consider the concept of synergy in each set.

\subsubsection{The use of Choquet integral in proposed approach}

The Choquet integral is given by 'Gustave Choquet' (Choquet 1954) and introduced into the fuzzy measure community by 'Murofushi and Sugeno' [53]. It is considered as an adequate substitute to the weighted arithmetic mean because it proposes to define a weight to each element and each subset of elements [49]. The use of the Choquet integral as an aggregation tool of interacting elements in multicriteria decision problems has been proposed by several authors [54-57,47]. We propose to use this integral to aggregate a data of the proposed bipolar hierarchical approach.

Let $X=\left\{x_{1}, x_{2}, \ldots, x_{n}\right\}$ be the set of numerically valued elements to aggregate by Choquet integral, to consider potential interactions, a fuzzy or capacity measure noted ' $v$ ' must be defined as follows:

Definition 1 (:). Let $2^{x}$ be the power set of X, a function $v: 2^{x} \rightarrow$ [01] is a capacity or a fuzzy measure over $\mathrm{X}$ if it verifies:

i) $v(\emptyset)=0, v(X)=1$,

ii) $\mathrm{S} \subseteq \mathrm{T} \Rightarrow \mathrm{v}(\mathrm{S}) \leq \mathrm{v}(T), \forall \mathrm{S}, \mathrm{T} \subseteq \mathrm{X}$

iii) For each $S \subseteq X, v(S)$ can be interpreted as the weight of the importance of the combination of elements of the set $S$ (relative weights to $S$ ). The Choquet integral of vector $x$ of elements of the set $\mathrm{X}$ associated to the capacity or fuzzy measure is given by Eq. (6).

$C_{v}(x):=\sum_{i=1}^{n}\left\{v\left(A_{(i)}\right)\left(x_{(i)}-x_{(i-1)}\right)\right\}$

where (.) is a permutation over a set $X \operatorname{such}$ as $x_{(1)} \leq \ldots \leq x_{(n)}, x_{(0)}=$ 0 and $A_{(i)}=\{(i), \ldots,(n)\}$.

For more details on the axiomatic characterizations of Choquet integrals, interested readers can consult the following references: $[58,52,50]$. The difficulty of computing Choquet integral is to define a fuzzy measure over the set $X$ that necessitates obtaining $2^{x}-2$ coefficients that represent the measure of subsets of $X$ other than $\emptyset$ and $X$. When the classification of elements can be realized by assigning them relative importance normalized weights, we propose to use a weighted cardinal fuzzy measure (WCFM) that leads to a straightforward formula for the corresponding Choquet integral [54].

Definition 2 (:). A weighted cardinal fuzzy measure (WCFM) over $\mathrm{X}$ associated to a relative normalized weights vector $\omega=\left[\omega_{1}, \omega_{2}\right.$, $\left.\ldots, \omega_{n}\right]$ is given by Eq. (7).

$v(\Theta)=\frac{|\Theta|}{|X|}\left(\sum_{j \in \Theta} \omega_{j}\right)$

where $\Theta$ is a subset of X.

It is straightforward to verify that this function fulfills conditions of a capacity or fuzzy measure. Let us denote by $C^{\omega}(x)$, the Choquet integral of numerical $n$ dimension vector $x$ associated to a WCFM with relative vector, then this integral, is given by Eq. (8).

$C^{\omega}(x)=\sum_{k=1}^{n}\left\{\left(\left(\frac{n-(k-1)}{n}\right)\left(\sum_{j \in A_{(k)}} \omega_{j}\right)\right)\left(x_{(k)}-x_{(k-1)}\right)\right\}$ where (.) indicated a permutation on the set $X$ such as $x_{(1)} \leq \ldots \leq x_{(n)}, x_{(0)}=0$, and $\mathrm{A}_{(k)}$ is defined by $\mathrm{A}_{(k)}=\{(k), \ldots,(n)\}$.

Using presented Choquet integral, the aggregation levels of proposed model can be summarized by the following algorithm.

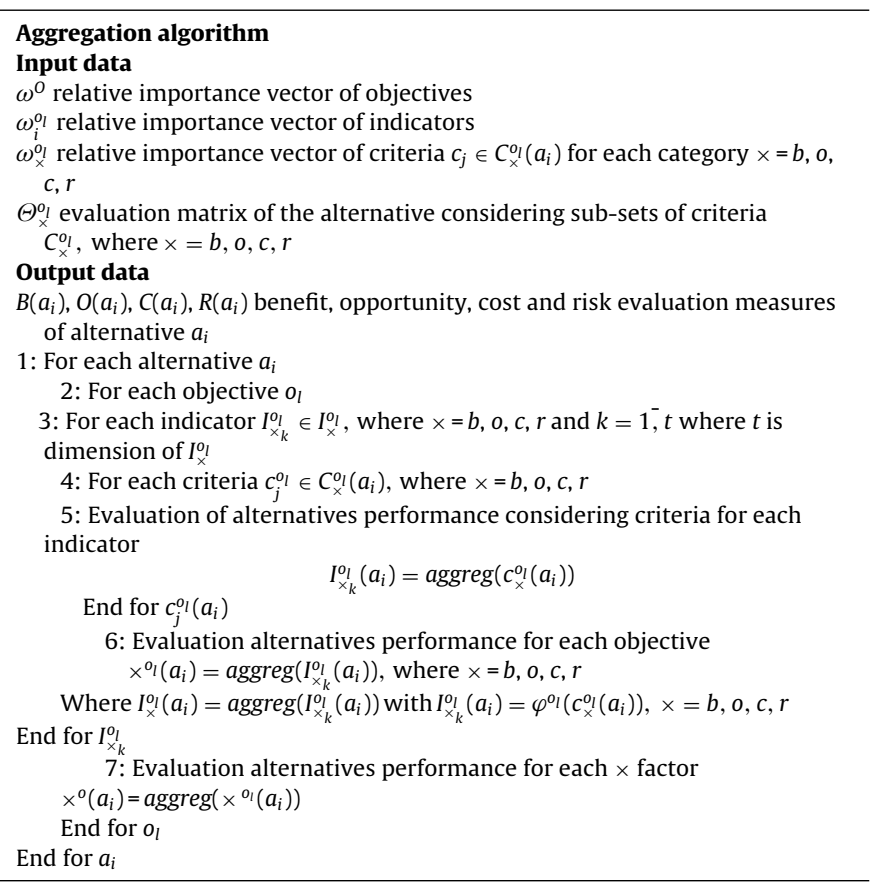

These levels of aggregation allow representing each alternative with $b, o, c, r$ factors. The aggregation function aggreg is replaced by the Choquet integral. For example, the aggregation of criteria on an indicator $I_{\times_{k}}^{O_{l}}$ may be given by the following expression:

$$
\begin{aligned}
I_{\times k}^{O_{l}}\left(a_{i}\right)= & \operatorname{aggreg}\left(c_{\times}^{O_{l}}\left(a_{i}\right)\right) \\
= & \sum_{k=1}^{m_{\times}}\left\{\left(\left(\frac{m_{\times}-(k-1)}{m_{\times}}\right)\left(\sum_{c_{j}^{o} l \in C_{\times}^{o_{l}}} \omega_{\times}^{o_{l}}\left(c_{j}^{o_{l}}\right)\right)\right)\right. \\
& \left.\left(\Theta_{\times}^{o_{l}}\left(a_{i}, c_{j}^{o_{l}}\right)_{(i)}-\Theta_{\times}^{o_{l}}\left(a_{i}, c_{j}^{o_{l}}\right)_{(i-1)}\right)\right\}
\end{aligned}
$$

where $\times=b, o, c, r$ and $m_{\times}$is the dimension of the considered criteria set.

Given the bipolar nature of the criteria, we propose the use of satisficing game theory as flexible recommendation tool for final evaluation process in order to represent each alternative with a supporting measure (represented by benefit and opportunity) and rejecting measure (represented by cost and risk). In the following, a brief description of the satisficing game theory is presented before addressing the application example.

\subsection{Satisficing game theory}

The philosophy behind the majority of the techniques used in the literature for the construction of an evaluation model is based on the superlative rationality [59] in which all alternatives must be compared to each other in the aim of optimality seeking. However, decision makers in solving real world problems do not necessarily seek the optimal solution, often costly in terms of time and money, but a satisfactory solution whose capabilities are estimated fairly good regarding to objective achievement [60]. The satisficing game theory is based on this observation and provides adequate tools for the selection of acceptable alternatives. The concept of being good 
enough is suitable for our approach, where an alternative can be considered good enough when its supporting contribution exceeds the rejecting one. To this end, each alternative $a_{i}$ will be characterized by a selectability measure $\mu_{S}\left(a_{i}\right)$ that estimates the extent to which $a_{i}$ complies with the overall goal and rejectability measure $\mu_{r}\left(a_{i}\right)$ that represents the cost associated with alternative $a_{i}$. In BOCR framework, the selectability measure corresponds to the aggregation of benefit and opportunity factors and the rejectability measure corresponds to the aggregation of cost and risk as shown in Eqs. (10) and (11) [61].

$$
\begin{aligned}
& \psi_{s}\left(a_{i}\right)=\delta B\left(a_{i}\right)+(1-\delta) O\left(a_{i}\right) \\
& \psi_{r}\left(a_{i}\right)=(1-\delta) C\left(a_{i}\right)+\delta R\left(a_{i}\right)
\end{aligned}
$$

where $B\left(a_{i}\right), O\left(a_{i}\right), C\left(a_{i}\right), R\left(a_{i}\right)$ are the evaluation results of alternative $a_{i}$ considering respectively, benefit, opportunity, cost and risk factors.

$0 \leq \delta \leq 1$ : is the risk aversion index. It permits to consider the risk aversion attitude of a decision maker on selection phase. The more $\delta$ is close to 1 , the greater is the risk aversion of decision maker who, being pessimistic, will tend to give more importance to risk than cost in rejectability measure (Eq. (11)) and penalize opportunity in favor of benefit in selectability measure (Eq. (10)). Inversely, when the risk aversion index tends to 0 , the decision maker is considered as optimistic. He will focus on opportunity to benefit in the selectability measure, and will overlook risk against cost in the rejectability measure.

Finally, selectability and rejectability functions are given respectively by the following Eqs. (12) and (13).

$\mu_{s}\left(a_{i}\right)=\frac{\psi_{s}\left(a_{i}\right)}{\sum_{v_{i} \in A} \psi_{s}\left(v_{i}\right)}$
$\mu_{r}\left(a_{i}\right)=\frac{\psi_{r}\left(a_{i}\right)}{\sum_{v_{i} \in A} \psi_{r}\left(v_{i}\right)}$

The satisficing game theory is characterized by several sets that can be used on recommendation phase to select the proposed solution(s).

The satisficing set $\mathrm{S}_{q} \subseteq A$ (at a boldness or caution index $q$ ) is the set of alternatives defined as following (Eq. (14)).

$S_{q}=\left\{a_{i} \in A: \mu_{S}\left(a_{i}\right) \geq q \mu_{r}\left(a_{i}\right)\right\}$

$q$ : is the caution index used to adjust the aspiration level. Increasing $q$ allows reducing the size of satisficing set $S_{q}$ (if too many alternatives are declared satisficing). On the contrary decreasing $q$ leads to a growing satisficing set (if $S_{q}$ is empty for instance) (Fig. 4).

A sensitivity analysis can be performed to determine the "threshold' value of caution index noted $\boldsymbol{q}_{\mathbf{m i n}}$ below which all alternatives are satisficing and the maximum value of the caution index noted $\boldsymbol{q}_{\max }$ above which no alternative is satisficing. For all satisficing

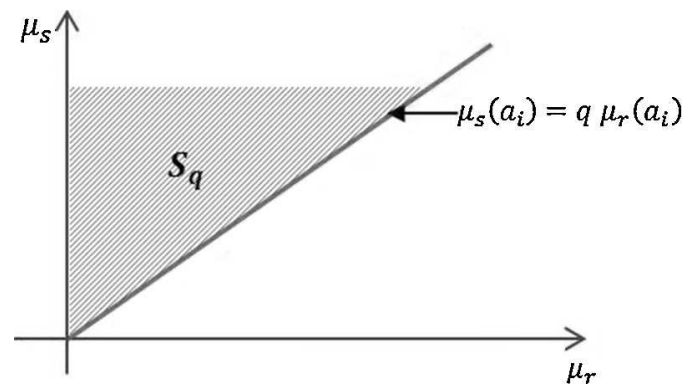

Fig. 4. Graphical representation of a satisficing set.

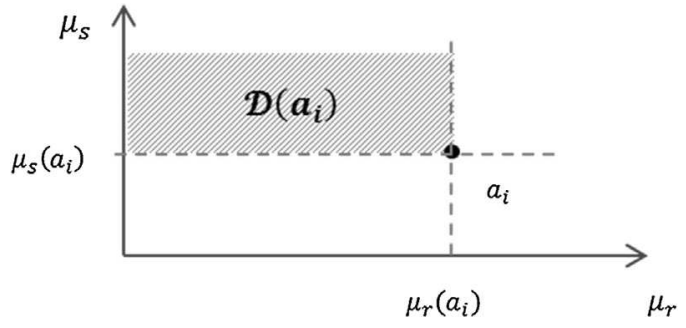

Fig. 5. Graphical representation of non-dominated alternatives.

alternatives, the inequality (15) must be checked such as, for caution index $\boldsymbol{q}$ there is $\boldsymbol{S}_{\boldsymbol{q}}=A$.

$\mu_{s}\left(a_{i}\right) \geq q \mu_{r}\left(a_{i}\right), \forall a_{i} \in A \Leftrightarrow q \leq q_{\min }=\min _{a_{i} \in A}\left(\frac{\mu_{s}\left(a_{i}\right)}{\mu_{r}\left(a_{i}\right)}\right)$

On the contrary, there is no satisfactory alternative $S_{q}=\emptyset$ if and only if the inequality (16) below is satisfied.

$\mu_{s}\left(a_{i}\right)\left\langle q \mu_{r}\left(a_{i}\right) \forall a_{i} \in A \Leftrightarrow q\right\rangle q_{\max }=\max _{a_{i} \in A}\left(\frac{\mu_{s}\left(a_{i}\right)}{\mu_{r}\left(a_{i}\right)}\right)$

Let us notice also that sometimes some satisficing alternatives can be dominated by others alternatives presenting a higher selectability measure and a lower rejectability measure. To identify these alternatives an equilibrium set $\varepsilon$ is defined as follows.

$\varepsilon=\left\{a_{i} \in A: \mathcal{D}\left(a_{i}\right)=\phi\right\}$

where $\mathcal{D}\left(a_{i}\right)$ is the set of alternatives that are strictly better than $a_{i}$. The set $\mathcal{D}\left(a_{i}\right)$ is defined with Eq. (18) (Fig. 5).

$\mathcal{D}\left(a_{i}\right)=D_{s}\left(a_{i}\right) \cup D_{r}\left(a_{i}\right)$

where $D_{s}\left(a_{i}\right)$ and $D_{r}\left(a_{i}\right)$ are defined as follows:

$D_{s}\left(a_{i}\right)=\left\{a_{i^{\prime}} \in A: \mu_{r}\left(a_{i}\right)<\mu_{r}\left(a_{i}\right)\right.$ and $\left.\mu_{s}\left(a_{i}\right) \geq \mu_{s}\left(a_{i}\right)\right\}$

$D_{r}\left(a_{i}\right)=\left\{a_{i^{\prime}} \in A: \mu_{r}\left(a_{i}\right) \leq \mu_{r}\left(a_{i}\right)\right.$ and $\left.\mu_{s}\left(a_{i}\right)>\mu_{s}\left(a_{i}\right)\right\}$

The satisficing equilibrium set $\varepsilon_{q}^{s}$ is given by Eq. (21).

$\varepsilon_{q}^{s}=\varepsilon \cap S q$

The satisficing equilibrium set $\varepsilon_{q}^{s}$ constitutes a Pareto equilibrium which means that the alternatives in this set are incomparable. A graphical representation of the alternatives can be done in the plane $\left(\mu_{s}\left(a_{i}\right), \mu_{r}\left(a_{i}\right)\right)$ as shown in Fig. 6 . The satisficing Pareto set is given by the portion located on the hatched curve above the straight line between the satisficing and not satisficing alternatives. Considering a discrete number of alternatives, the proposed approach is based on simple Pareto front algorithm where satisficing alternatives are identified first by comparing their selectability and rejectability measures. Then, the non-dominated sets of alternatives are identified by considering distances between alternatives. The pareto frontier are obtained thereafter considering the intersection of satisficing and non-dominated alternative.

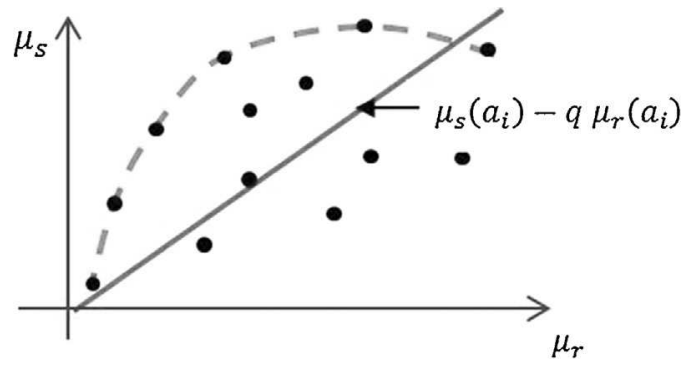

Fig. 6. Graphic representation of alternatives in the plane $\left(\mu_{s}, \mu_{r}\right)$. 
In the recommendation phase, the ranking or the selection of final solution(s) can be obtained from satisficing equilibrium set using a selection criterion. The selection and the ranking are the relative evaluation operations that can be performed on the set of alternatives $A$ through a selection criteria noted 'cs' [62]. The selection criteria can be determined by a value function noted $\pi\left(a_{i}\right)$ defined in terms of selectability measure $\mu_{s}$ and rejectability measure $\mu_{r}$, as follows ([39]).

$\pi\left(a_{i}\right)=\pi\left(\mu_{S}\left(a_{i}\right), \mu_{r}\left(a_{i}\right)\right) \quad \forall a_{i} \in \varepsilon_{q}^{S}$

The value function $\pi\left(a_{i}\right)$ can take several forms depending on the decision goal, for example:

$\mathbf{s c}_{1}: \pi\left(a_{i}\right)=\mu_{S}\left(a_{i}\right)-q \mu_{r}\left(a_{i}\right) \quad \forall a_{i} \in \varepsilon_{q}^{S}$

that gives the priority to alternatives with large difference between the selectability measure and the rejectability measure given the index of caution $q$, or

$\mathbf{s c}_{2}: \pi\left(a_{i}\right)=\mu_{S}\left(a_{i}\right) / q \mu_{r}\left(a_{i}\right) \quad \forall a_{i} \in \varepsilon_{q}^{S}$

that considers alternatives with the largest index of caution, or

$$
\text { (25) } \pi\left(a_{i}\right)=\mu_{s}\left(a_{i}\right)\left(\text { respect } \cdot \pi\left(a_{i}\right)=\frac{1}{\mu_{r}\left(a_{i}\right)}\right) \quad \forall a_{i} \in \varepsilon_{q}^{S} \text { that gives }
$$

priority to alternatives with the largest selectability (respect. lowest rejectability); this later case is suitable when one of the measure is uniformly distributed over alternatives. The value function can then be used to select the ultimate alternative $a_{i}^{*}$ as follows (Eq. (26)).

$$
a_{i}^{*}=\underset{a_{i} \in \varepsilon_{q}^{S}}{\operatorname{argmax}} \pi\left(a_{i}\right)
$$

or to rank alternatives using the relation given by Eq. (27)

$a_{i} \succcurlyeq a_{i^{\prime}} \Leftrightarrow \pi\left(a_{i}\right) \geq \pi\left(a_{i}\right) \quad \forall a_{i}, a_{i^{\prime}} \in \varepsilon_{q}^{S}$

The preference relation $\succcurlyeq$ indicates that alternative $a_{i}$ is better than alternative $a_{i^{\prime}}$.

A global sensitivity analysis would study the variability of inputs and their impact on the output result. This analysis can be used to validate the proposed and guide research efforts and development method. Given the hierarchical decomposition, variation calculus from operational level to final measures is rendered easy in a chaining process; so that a sensitivity analysis scheme can be easily considered in order to measure the robustness of selected alternative.

\section{Case study}

The developed approach is applied to solve the scrapped aircraft withdrawal plan location problem. This paper investigating a centralized reverse supply chain structure due to the significant economic advantage it has in the context of localization strategies [63]. Indeed, the centralized structure allows minimizing the investments of restatement process which often requires specific test equipment and a qualified workforce, as emphasizes on reverse logistics literature. In addition, the concentration of returns in one place allows economies of scale by volume effect and a wider range of possibilities for rework and therefore additional revenue opportunities [64].

Considering a bipolar context where positive and negative aspects are evaluated distinctly, AHP procedure combined to BOCR analysis is used to select the most satisficing aircraft dismantling site among seven potential locations in decision problem, discussed initially in [13]. The materials of considered problem are adapted and re-organized to the approach established in this paper. The overall goal of the problem is to repatriate an EOL aircraft to a dismantling platform. Economic, environmental and social objectives have been fixed by the group decision. The indicators used

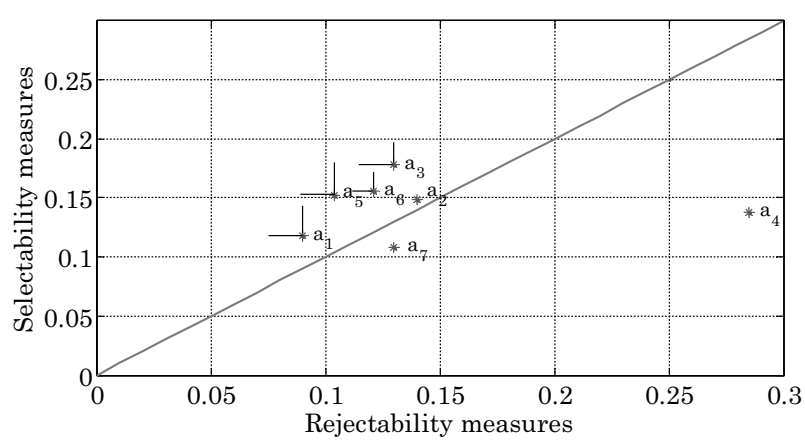

Fig. 7. Alternative representation in $\left(\mu_{r}, \mu_{s}\right)$ plane for $(\delta=0.5)$.

to calculate the achievement degree of objectives are elicited by decision makers for each objective and detailed in quantifiable criteria characterizing the alternatives in BOCR analysis framework (Tables 2-4).

The evaluation of alternatives using proposed AHP-BOCR approach starts with the determination of the decision parameter weights (objectives, indicators, criteria) using a pairwise comparison in each hierarchical level, Eqs. (2) and (3) are used to deduce parameter weights. The numerical evaluation of alternatives is then realized, the pairwise comparison matrix in this case are deduced with Eq. (4). The Numerical evaluation (quantitative and qualitative) of alternative considering economic objective for example, is given in Table 5.

Considering BOCR framework, from different performance and weights matrices, a proposed approach through Eq. (5) has been done to obtain the evaluation of each alternative with regard to criteria in terms of matrices $\theta_{\times}^{o_{l}}$ for each category. The BOCR analysis of objectives is deduced using proposed aggregation method and summarized in Table 6.

Finally, considering all objectives, the selectability measure (benefit and opportunity) and the rejectability measure (cost and risks) are deduced based on the satisficing game theory formalism through Eqs. (10)-(13). Considering that decision makers have an average risk aversion $(\delta=0.5)$ given the equal importance to certain parameters (benefit and cost) and uncertain ones (opportunity and risk), the results are summarized in Table 7 and the graphical representation of the alternatives is shown in Fig. 7. Showing alternatives positions in the plane $\left(\mu_{s}, \mu_{r}\right)$ may be of a great aid for analysis (mainly when there is a great number of alternatives) as this allows to visualize equilibria, satisficing, not satisficing alternatives. For a particular alternative one can determine alternatives that may dominate it; this information can be used to guide a sensitivity analysis process for trade-off seeking for instance and facilitates dialog between the analyst and the decision group.

Assuming that the caution index (red line in Fig. 7) is equal to 1 $(q=1)$ with $q \in[0,481,46]$, an alternative is considered satisfactory if its selectability measure is greater or equal to its rejectability measure, thus, the satisficing equilibrium set in this case consists on alternatives $a_{1}, a_{3}, a_{5}, a_{6}$ which are not dominated and have selectability measure greater of their rejectability measures $\left(\varepsilon_{1}^{s}=\right.$ $\left.\left\{a_{1}, a_{3}, a_{5}, a_{6}\right\}\right)$. The graphical representation shows also that alternative $a_{2}$, although satisfactory, is not in equilibrium set because of its domination by other alternatives. The alternative $a_{4}$ is considered unsatisfactory on the other hand.

A sensitive analysis can be realized by varying index caution $q \in[0,481,46]$ to identify stable alternatives; considering that decision maker presents a low caution ( $q=0.6$ for example), only alternative $a_{4}$ is not satisficing because of its low performance and a satisficing equilibrium set consists on $\varepsilon_{0,6}^{s}=\left\{\mathrm{a}_{1}, \mathrm{a}_{3}, \mathrm{a}_{5}, \mathrm{a}_{6}\right\}$. Conversely, when decision maker presents a high caution $(q=1.2$ for example), caution expressed is reflected in the selection of 
Table 2

Evaluation data for economical objective.

\begin{tabular}{|c|c|c|c|}
\hline Factors & Indicators & Criteria & Unit \\
\hline Benefit & $\begin{array}{l}\text { Recycled products } \\
\text { Reused products } \\
\text { Energy value } \\
\text { Resources }\end{array}$ & $\begin{array}{l}\text { \% Of materials to be recycled } \\
\text { Price or value of materials to be recycled } \\
\% \text { Of parts of systems to be reused } \\
\text { Resale value of spare parts } \\
\% \text { Of waste } \\
\text { Energy value } \\
\% \text { Of use of resources } \\
\text { Distance traveled with } 1 \mathrm{~T} \text { of freight with } 11 \text { of fuel } \\
\text { Volume of the material } \\
\% \text { Of skilled labor }\end{array}$ & $\begin{array}{l}\% \\
\text { Euro/kg } \\
\% \\
\text { Euro/un } \\
\% \\
\text { Euro/kg } \\
\% \\
\mathrm{kmt} / \mathrm{l} \\
\text { Units } \\
\%\end{array}$ \\
\hline Opportunity & $\begin{array}{l}\text { Forecast orders } \\
\text { Possible profits }\end{array}$ & $\begin{array}{l}\text { Forecast quantity of parts and system components } \\
\text { Frequency components required } \\
\text { Volume of the material } \\
\text { Profit taxes } \\
\text { Profit appropriation }\end{array}$ & $\begin{array}{l}\text { Units } \\
1 / \text { year } \\
\text { Unities } \\
\text { Euros } \\
\text { Euros }\end{array}$ \\
\hline Cost & $\begin{array}{l}\text { Cost of production } \\
\text { Administration cost }\end{array}$ & $\begin{array}{l}\text { Place of dismantling distance } \\
\text { Cost/km } \\
\text { Travel time } \\
\text { Location cost } \\
\text { Cost of ownership (depreciation) } \\
\text { Working hours } \\
\text { Hourly cost } \\
\text { Parking time prior to the dismantling } \\
\text { Service life } \\
\text { Service cost } \\
\text { Management costs (doc, training) }\end{array}$ & $\begin{array}{l}\text { km } \\
\text { Euro/km } \\
\text { Days } \\
\text { Euro } \\
\text { Euros } \\
\text { Days } \\
\text { Euros } \\
\text { Days } \\
\text { Days } \\
\text { Euros } \\
\text { Euros }\end{array}$ \\
\hline Risk & Opportunity cost & $\begin{array}{l}\text { \% Of skilled labor } \\
\text { Resources in the best alternative } \\
\text { Volume of the material }\end{array}$ & $\begin{array}{l}\% \\
\text { Euros } \\
\text { Units }\end{array}$ \\
\hline
\end{tabular}

Table 3

Evaluation data for environmental objective.

\begin{tabular}{|c|c|c|c|}
\hline Factors & Indicators & Criteria & Unit \\
\hline Benefit & Recycling/reuse & $\begin{array}{l}\text { \% Of materials to be recycled } \\
\% \text { Of parts of systems to be reused } \\
\% \text { Waste } \\
\text { Presence of hazardous materials } \\
\text { Frequency components required } \\
\text { Volume of the material } \\
\text { Value recyclable materials } \\
\text { Resale value of coins } \\
\% \text { Of use of resources used } \\
\% \text { Of skilled labor }\end{array}$ & $\begin{array}{l}\% \\
\% \\
\% \\
1 \\
1 / \text { year } \\
\text { Unit } \\
\text { Euro/unit } \\
\text { Euro/unit } \\
\% \\
\%\end{array}$ \\
\hline Opportunity & Gain & $\begin{array}{l}\text { Distance traveled with } 1 \mathrm{~T} \text { of freight with } 1 \mathrm{l} \text { of fuel } \\
\text { Volume of the material } \\
\text { Level of stakeholder satisfaction } \\
\text { Frequency components required }\end{array}$ & $\begin{array}{l}\mathrm{km} * \mathrm{t} / \mathrm{l} \\
\text { Unit } \\
\text { / } \\
1 / \text { year }\end{array}$ \\
\hline Cost & $\begin{array}{l}\text { Recycling } \\
\text { Packaging }\end{array}$ & $\begin{array}{l}\text { \% Of waste untreated } \\
\text { Number of people affected } \\
\text { Hourly cost } \\
\text { Working time } \\
\text { Parking time before the deconstruction } \\
\text { Cost/km } \\
\text { Travel time } \\
\text { Rental cost } \\
\text { Cost of service } \\
\text { Management costs } \\
\text { Service life }\end{array}$ & $\begin{array}{l}\% \\
\text { Persons } \\
\text { Euros } \\
\text { Days } \\
\text { Days } \\
\text { Euros/km } \\
\text { Days } \\
\text { Euros } \\
\text { Euros } \\
\text { Euros } \\
\text { Days }\end{array}$ \\
\hline Risks & Pollution & $\begin{array}{l}\text { Level of air quality } \\
\text { Level of pollution of water resources } \\
\text { Level of soil pollution } \\
\text { kwh consumed by ton of commodity } \\
\% \text { Of skilled labor }\end{array}$ & $\begin{array}{l}\text { / } \\
\text { / } \\
\%\end{array}$ \\
\hline
\end{tabular}


Table 4

Evaluation data for social objective.

\begin{tabular}{|c|c|c|c|}
\hline Factors & Indicators & Criteria & Unit \\
\hline Benefit & $\begin{array}{l}\text { Comfort } \\
\text { Employment } \\
\text { Yield }\end{array}$ & $\begin{array}{l}\text { Level of air quality } \\
\text { Number of employees } \\
\text { Level of stakeholder satisfaction } \\
\text { Travel time } \\
\text { Working hours } \\
\text { Service life }\end{array}$ & $\begin{array}{l}\text { / Persons } \\
\text { / } \\
\text { Days } \\
\text { Days } \\
\text { Days }\end{array}$ \\
\hline Opportunity & $\begin{array}{l}\text { Employment } \\
\text { Environment }\end{array}$ & $\begin{array}{l}\text { \% of skilled labor } \\
\text { Level of air quality } \\
\text { Level of soil pollution }\end{array}$ & $\begin{array}{l}\% \\
1 \\
1\end{array}$ \\
\hline Cost & $\begin{array}{l}\text { Accidents } \\
\text { Sound incident }\end{array}$ & $\begin{array}{l}\text { Frequency rate of accidents with stop } \\
\text { Severity rate } \\
\text { Number of people affected } \\
\text { Average decibel }\end{array}$ & $\begin{array}{l}1000 \% \\
\% \\
\text { Persons } \\
\text { Db }\end{array}$ \\
\hline Risk & $\begin{array}{l}\text { Pollution } \\
\text { Infections }\end{array}$ & $\begin{array}{l}\text { Level of pollution of water resources } \\
\text { Level of soil pollution } \\
\text { Presence of hazardous materials } \\
\text { Number of people affected }\end{array}$ & $\begin{array}{l}1 \\
1 \\
\text { Persons }\end{array}$ \\
\hline
\end{tabular}

Table 5

Numerical evaluation of alternatives considering criteria of economic objective.

\begin{tabular}{|c|c|c|c|c|c|c|c|c|}
\hline Criteria of economic objective & $a_{1}$ & $a_{2}$ & $a_{3}$ & $a_{4}$ & $a_{5}$ & $a_{6}$ & $a_{7}$ & Unit \\
\hline$\%$ Of materials to be recycled & 0.55 & 0.4 & 0.63 & 0.68 & 0.65 & 0.08 & 0.25 & $\%$ \\
\hline Price or value of materials to be recycled & 50 & 30 & 45 & 25 & 60 & 35 & 35 & Euros/kg \\
\hline$\%$ Of parts of systems to reuse & 0.35 & 0.4 & 0.3 & 0.2 & 0.25 & 0.15 & 0.6 & $\%$ \\
\hline Resale value of spare parts & 150 & 100 & 300 & 500 & 200 & 150 & 100 & Euros/unit \\
\hline$\%$ Of waste & 0.08 & 0.25 & 0.05 & 0.1 & 0.08 & 0.03 & 0.13 & $\%$ \\
\hline Energy value & 15 & 10 & 15 & 13 & 1 & 12 & 10 & Euro/kg \\
\hline$\%$ Of use of resources & 0.85 & 0.65 & 0.9 & 0.825 & 0.75 & 0.6 & 0.66 & $\%$ \\
\hline Distance traveled with $1 \mathrm{~T}$ of freight with 11 of fuel & 50 & 45 & 80 & 200 & 250 & 70 & 50 & $\mathrm{kmt} / \mathrm{l}$ \\
\hline Volume of the material & 10,000 & 120,000 & 150,000 & 17,000 & 13,000 & 70,000 & 10,000 & Units \\
\hline$\%$ Of skilled labor & 0.3 & 0.6 & 0.85 & 0.75 & 0.6 & 0.9 & 0.5 & $\%$ \\
\hline Forecast quantity of parts and system components & 10,000 & 10,000 & 10,000 & 15,000 & 12,000 & 70,000 & 80,000 & Units \\
\hline Required components frequency & 40 & 30 & 60 & 50 & 40 & 55 & 50 & $1 /$ years \\
\hline Volume of the material & 10,000 & 120,000 & 150,000 & 17,000 & 13,000 & 70,000 & 10,000 & Units \\
\hline Profit taxes & 2000 & 1000 & $3,000,000$ & 2000 & 15,000 & $5,000,000$ & 150,000 & Euros \\
\hline Profit appropriation & 45,000 & 10,000 & 400 & 100 & 150,000 & 50 & 50 & Euros \\
\hline Place of dismantling distance & 1500 & 300 & 2000 & 8000 & 1000 & 500 & 1000 & $\mathrm{~km}$ \\
\hline Cost $/ \mathrm{km}$ & 15 & 40 & 25 & 10 & 60 & 45 & 20 & Euro/km \\
\hline Travel time & 16 & 7 & 15 & 30 & 10 & 13 & 12 & Days \\
\hline Location cost & 25,000 & 30,000 & 75,000 & 5000 & 50,000 & 15,000 & 5000 & Euros \\
\hline Cost of ownership (depreciation) & 1000 & & 15 & 25 & 35 & 40 & 45 & Euros \\
\hline Working hours & 3 & 15 & 5 & 20 & 7 & 10 & 15 & Days \\
\hline Hourly cost & 120 & 300 & 45 & 100 & 90 & 75 & 50 & Euros \\
\hline Parking time prior to the dismantling & 200 & 100 & 50 & 90 & 130 & 250 & 200 & Days \\
\hline Service life & 260 & 150 & 100 & 90 & 150 & 300 & 350 & Days \\
\hline Cost of service & $2,000,000$ & $3,500,000$ & $1,500,000$ & $4,000,000$ & $2,000,000$ & $1,500,000$ & $3,000,000$ & Euros \\
\hline Management costs & 10,000 & 150,000 & 70,000 & 5000 & 10,000 & 15,000 & 120,000 & Euros \\
\hline$\%$ Of skilled labor & 0.3 & 0.6 & 0.85 & 0.75 & 0.6 & 0.9 & 0.5 & $\%$ \\
\hline Resources in the best alternative & $2,500,000$ & $3,000,000$ & $3,000,000$ & $3,000,000$ & $3,000,000$ & $3,000,000$ & $3,000,000$ & Euros \\
\hline Volume of the material & 10,000 & 120,000 & 150,000 & 17,000 & 13,000 & 70,000 & 10,000 & Units \\
\hline
\end{tabular}

Table 6

AHP evaluation matrix for $b, o, c, r$ factors.

\begin{tabular}{|c|c|c|c|c|c|c|c|c|}
\hline Objectives & $\theta_{\times}^{o_{l}}$ & $\mathrm{a}_{1}$ & $\mathrm{a}_{2}$ & $a_{3}$ & $\mathrm{a}_{4}$ & $a_{5}$ & $\mathrm{a}_{6}$ & $a_{7}$ \\
\hline \multirow[t]{4}{*}{ Economic objectives } & $x=\mathbf{b}$ & 0.13 & 0.15 & 0.17 & 0.18 & 0.15 & 0.10 & 0.12 \\
\hline & $x=\mathbf{0}$ & 0.08 & 0.12 & 0.24 & 0.04 & 0.20 & 0.26 & 0.06 \\
\hline & $x=c$ & 0.15 & 0.21 & 0.14 & 0.10 & 0.11 & 0.11 & 0.18 \\
\hline & $x=\mathbf{r}$ & 0.10 & 0.14 & 0.17 & 0.15 & 0.14 & 0.17 & 0.13 \\
\hline \multirow{4}{*}{$\begin{array}{l}\text { Environmental } \\
\text { objectives }\end{array}$} & $x=\mathbf{b}$ & 0.13 & 0.14 & 0.16 & 0.16 & 0.15 & 0.13 & 0.12 \\
\hline & $x=\mathbf{0}$ & 0.09 & 0.18 & 0.19 & 0.16 & 0.15 & 0.14 & 0.08 \\
\hline & $x=c$ & 0.03 & 0.19 & 0.11 & 0.36 & 0.07 & 0.06 & 0.15 \\
\hline & $x=\mathbf{r}$ & 0.09 & 0.13 & 0.15 & 0.16 & 0.13 & 0.21 & 0.14 \\
\hline \multirow[t]{4}{*}{ Social objectives } & $x=\mathbf{b}$ & 0.16 & 0.14 & 0.13 & 0.18 & 0.11 & 0.14 & 0.13 \\
\hline & $x=\mathbf{0}$ & 0.13 & 0.16 & 0.15 & 0.13 & 0.14 & 0.14 & 0.15 \\
\hline & $x=c$ & 0.09 & 0.04 & 0.09 & 0.52 & 0.10 & 0.08 & 0.09 \\
\hline & $x=\mathbf{r}$ & 0.06 & 0.09 & 0.10 & 0.52 & 0.06 & 0.08 & 0.08 \\
\hline
\end{tabular}


Table 7

Selectability and rejectability measures for the considered application $(\delta=0.5)$.

\begin{tabular}{lllllll}
\hline Bipolar measures & $\mathrm{a}_{1}$ & $\mathrm{a}_{2}$ & $\mathrm{a}_{3}$ & $\mathrm{a}_{4}$ & $\mathrm{a}_{5}$ & $\mathrm{a}_{6}$ \\
\hline$\mu_{s}\left(a_{i}\right)$ & 0.118 & 0.149 & 0.178 & 0.138 & 0.152 \\
$\mu_{r}\left(a_{i}\right)$ & 0.090 & 0.140 & 0.130 & 0.285 & 0.156 & 0.104 \\
\hline
\end{tabular}

Table 8

Ranked alternatives.

\begin{tabular}{|c|c|c|c|c|c|c|c|}
\hline \multirow[t]{2}{*}{ Selection criteria } & \multicolumn{7}{|c|}{ Alternatives } \\
\hline & $\mathrm{a}_{1}$ & $a_{2}$ & $\mathrm{a}_{3}$ & $\mathrm{a}_{4}$ & $a_{5}$ & $\mathrm{a}_{6}$ & $\mathrm{a}_{7}$ \\
\hline $\operatorname{cs} 1$ & 4 & 5 & 1 & 7 & 2 & 3 & 6 \\
\hline $\operatorname{cs} 2$ & 3 & 5 & 2 & 7 & 1 & 4 & 6 \\
\hline \multirow{2}{*}{ cs3 } & 6 & 4 & 1 & 5 & 3 & 2 & 7 \\
\hline & 1 & 6 & 4 & 7 & 2 & 3 & 4 \\
\hline Final ranking & 4 & 5 & 1 & 7 & 2 & 3 & 6 \\
\hline
\end{tabular}

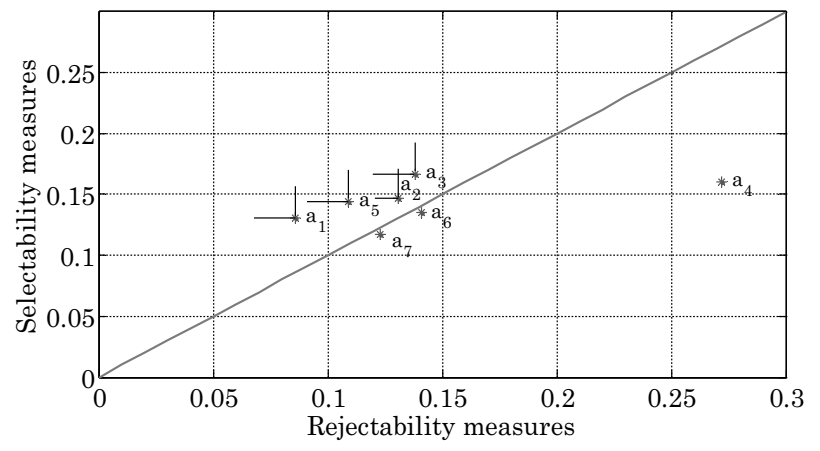

Fig. 8. Alternative representation in $\left(\mu_{s}, \mu_{r}\right)$ plane for $(\delta=0.8)$.

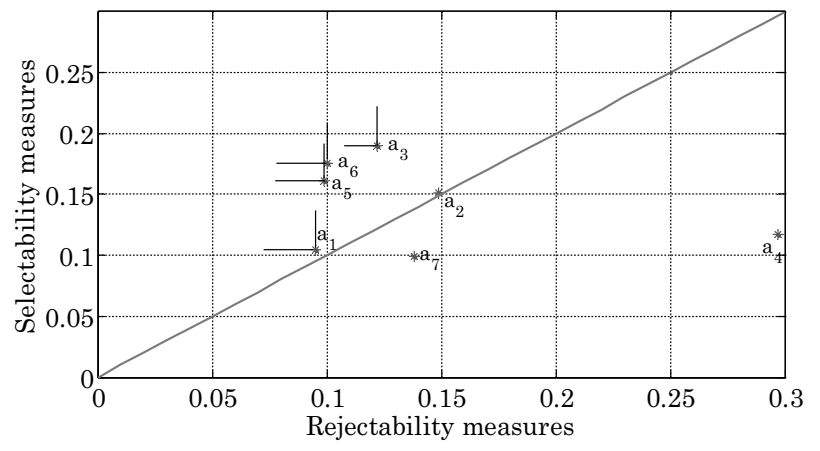

Fig. 9. Alternative representation in $\left(\mu_{s}, \mu_{r}\right)$ plan for $(\delta=0.2)$. alternatives that have the lowest levels of rejectability, in this case satisficing equilibrium set is $\varepsilon_{1,2}^{s}=\left\{\mathrm{a}_{1}, \mathrm{a}_{3}, \mathrm{a}_{5}, \mathrm{a}_{6}\right\}$ when the rest of alternatives is considered non-satisficing. The final solution can be deduced using proposed selection criteria with Eqs. (23)-(25) from satisficing equilibrium set $\left(\varepsilon_{1}^{s}=\varepsilon_{0,6}^{s}=\varepsilon_{1,2}^{s}=\left\{\mathrm{a}_{1}, \mathrm{a}_{3}, \mathrm{a}_{5}, \mathrm{a}_{6}\right\}\right)$ as shown in Table 8 where the ultimate dominance structure is given by Eq. (28).

$a_{3} \succcurlyeq a_{5} \succcurlyeq a_{6} \succcurlyeq a_{1}$

The proposed approach involves external factors of caution and risk aversion to express a human behavior that can significantly alter the final selection. To illustrate this, we propose to consider two extreme cases, when a 'pessimistic' decision maker expresses a strong risk aversion $(\delta=0.8)$ and the case of an optimistic decision maker whose rate of risk aversion is low $(\delta=0.2)$.

A strong risk aversion pushes generally the decision maker to focus on some certain gain while avoiding risk. Such behavior is reflected in the proposed approach by given more importance to risk in rejectability measure and focus on benefit in selectability measure. For pessimistic decision makers focusing on positive certain element (benefit) and negative uncertain element (risk) $(\delta=0.8$ ), the set of satisficing equilibrium contains the following alternatives $\left(\varepsilon_{0,8}^{s}=\left\{a_{2}, a_{3}, a_{5}, a_{1}\right\}\right)$, Fig. 8. Note that the alternative $a_{6}$ is replaced in this case by alternative $a_{2}$ in the satisficing equilibrium set. This is explained by the fact that the benefit and risk provided by the alternative 2 are more important than those presented by the alternative 6 . However the opportunity offered by the alternative 6 is greater than alternative 2 .

In the second case $(\delta=0.2)$, see Fig. 9, the decision maker is optimistic and bets on the potential of alternative (opportunity) neglecting the possible risk. This leads to prefer opportunity to benefit in selectability measure and cost to risk in rejectability measure. When decision makers have a low risk aversion, one will note that the satisficing equilibrium set contains the same satisficing equilibrium set as for $\delta=0.5\left(\varepsilon_{1}^{s}=\varepsilon_{0.2}^{s}=\left\{\mathrm{a}_{1}, \mathrm{a}_{3}, \mathrm{a}_{5}, \mathrm{a}_{6}\right\}\right)$ which means that the selected alternatives present a good evaluation on benefit, opportunity, cost and risk factors.

Considering a risk aversion index, the final solution can be obtained by the selection criteria defined in the previous section and/or a sensitivity analysis which would make vary the risk aversion index and select the most stable alternatives. In this case, one can easily observe that alternative $a_{3}$ is satisficing and dominant regardless of risk aversion, it can therefore be considered as an ultimate solution which joined the first analysis based on variation index caution. In case of group decision conflict, simulation of possible scenarios allows a better analysis of the alternative and human behavior impact for a better reflection for a consistent choice.

\section{Conclusion}

This paper addressed the problem of selecting a site for dismantling an EOL aircraft. After having described the dismantling process, a methodology has been introduced. Considering the problem as a multi-criteria/multi-objectives decision problem, the AHP procedure combined with BOCR analysis have been proposed to structure and address the problem issue. Given the bipolar nature of criteria distributed according to benefit, opportunity, cost and risk factors, the satisficing games theory has been proposed as the analysis tool for the final recommendation process. The risk aversion attitude that decision makers may present is taken into account in the model through the risk aversion index. The main contribution of this work is related to the structuring framework making easier the elicitation of problem characteristics in order to evaluate the different alternatives in the dismantling site location problem. The developed approach also proposes a flexible recommendation tool that integrates the human factor in the evaluation and allows analyze its impact by considering different scenarios. In the recommendation phase selectablity and rejectability measures 
were calculated integrating the concept of risk aversion to take into account the impact of the decision maker nature on the final ranking. This aggregation reveals the significant impact that the nature of individuals can have on their final choice. This approach provides ease of immersive excursion and can be assimilated to non-experts tool where the graphical results help facilitate dialog between analyst and decision makers. This proposal can be adapted to deal with complex decision problems including a multitude of characteristics considering design of reverse logistics network as multiproduct and/or multistage reverse logistic network problems and also in general decision fields involving group decision. Although the proposed flexible model has some new features such as those related to bipolar hierarchical structure, elicitation of criteria considering each objective and alternative and integration of the human factor, some weakness can be felt when applying the approach developed in this paper particularly due to the amount of parameters that have to be elicitated and the interpretation issues by decision makers mainly when they are trained in different backgrounds. But if the process is conducted by an analyst step by step, these difficulties may be reduced. The influence of EOL aircrafts characteristics in the reverse supply chain and disassembly choices can be considered in more general model.

Future works can address on the one hand some improvement considering more flexible bipolar structuration based on graphical models as Bayesian network to address the evaluation approximations for example. On the other hand, the evaluation and recommendation methods for group decision making problems can be developed considering that alternatives are represented with local preferences of each decision makers. The more general approach based on bipolar context can be developed considering the impact of human nature (fear, egoism, risk aversion, or influence) in evaluation process. The representation of interactions between decision elements can be done using graphical models such as Bayesian networks that can be used to address the approximations related to individual assessments and/or the representation of influences between decision makers. To achieve a common legitimate solution for the group decision, the consensus processes can also be developed. The satisficing game theory is an interesting mathematical tool to consider the recommendation phase. A sensitive analysis can be developed to show the impact of inputs data and potential influence on decision makers considering group decision on final results. Thanks to the flexible nature of the presented approach, it would also be interesting to develop it in solving strategic games problems. More elaborate process of achieving equilibrium may be subject of future developments in cooperative games and the various cases of coalitions for example. Non-cooperative games are also an untapped field of application. These perspectives can be offered for solving reverse logistics problems mentioned above but also decision making problem in more general fields.

\section{Contributors}

Study conception and design: Yasmina Bouzarour-Amokrane, Tchangani Ayeley, François Peres; Acquisition of data: Yasmina Bouzarour-Amokrane; Analysis and interpretation of data: Yasmina Bouzarour-Amokrane; Drafting of manuscript: Yasmina Bouzarour-Amokrane; Critical revision: Tchangani Ayeley, François Peres.

\section{References}

[1] Fleischmann M, Krikke HR, Dekker R, Flapper SDP. A characterisation of logistics networks for product recovery. OMEGA - Int J Manag Sci 2000;28(6):653-66.

[2] Lund RT. The remanufacturing industry: hidden giant. Boston University; 1996.

[3] Kerr W, Ryan C. Eco-efficiency gains from remanufacturing: a case study of photocopier remanufacturing at Fuji Xerox Australia. J Clean Prod 2001;9(February $(1)): 75-81$
[4] Godichaud M, Pérès FA, Tchangani P. Optimizing end-of-life system dismantling strategy. Int J Prod Res 2012;50(14):3738-54

[5] Godichaud M, Tchangani AP, Pérès F, Iung B. Sustainable management of endof-life systems. Prod Plan Control 2012;23(2-3):216-36.

[6] Dekker R, Fleischmann M, Inderfurth K, van Wassenhove LN. Reverse logistics quantitative models for closed-loop supply chains; 2004.

[7] Stock JR. Development and implementation of reverse logistics programs. 1st ed. Council of Logistics Management; 1998.

[8] Engineering and Physical Sciences Research Council. The aircraft at end of life sector a preliminary study. Swindon; 2007.

[9] Carberry W. Airplane Recycling Efforts Benefit Boeing Operators. Boeing AERO Mag QRT 2008, n. 130.76.96.105

[10] van Heerden D-J, Curran R. Value extraction from end-of-life aircraft. Encycl Aerosp Eng 2010, http://dx.doi.org/10.1002/9780470686652.eae355.

[11] Keivanpour S, Ait-Kadi D, Mascle C. Toward a strategic approach to end-oflife aircraft recycling projects a research agenda in transdisciplinary context. J Manag Sustain 2013;3(July (3))

[12] Nikolaou IE, Evangelinos KI, Allan S. A reverse logistics social responsibility evaluation framework based on the triple bottom line approach. J Clean Prod 2013;56:173-84.

[13] Lobato MA (Master thesis) Gestion des risques dans la logistique de démantèlement. Ecole Nationale d'Ingénieurs de Tarbes; 2011.

[14] Roghanian E, Pazhoheshfar P. An optimization model for reverse logistics network under stochastic environment by using genetic algorithm. J Manuf Syst 2014;33(July (3)):348-56.

[15] Sarkis J. A strategic decision framework for green supply chain management. J Clean Prod 2003:11(June (4)):397-409.

[16] Srivastava SK. Network design for reverse logistics. Omega 2008;36(August (4)):535-48

[17] Spengler T, Ploog M, Stolting W, Durr C. Disassembly planning in closed-loop supply chains: an ERP-based solution. Int J Integr Supply Manag 2004;1(2): 139.

[18] Stuart JA, Bonawi-tan W, Loehr S, Gates J. Reducing costs through improved returns processing. Int J Phys Distrib Logist Manag 2005;35(August (7)):468-80.

[19] Clarke AR, Zhang Q Gershenson JK, Sutherland JW. Selection of remanufacturing facility locations to minimise cost and environmental impact. In: LCE 2008 15th CIRP Int. Conf. Life Cycle Eng. Conf. Proc. 2008. p. 229.

[20] de Figueiredo JN, Mayerle SF. Designing minimum-cost recycling collection networks with required throughput. Transp Res Part E Logist Transp Rev 2008;44(September (5)):731-52.

[21] Ye L, Ye C, Chuang Y-F. Location set covering for waste resource recycling centers in Taiwan. Resour Conserv Recycl 2011;55(September (11)):979-85.

[22] Jayaraman V, Guide VDR, Srivastava R. A closed-loop logistics model for remanufacturing. J Oper Res Soc 1999;50(May (5)):497-508.

[23] Min H, Ko H-J. The dynamic design of a reverse logistics network from the perspective of third-party logistics service providers. Int J Prod Econ 2008;113(May (1)):176-92.

[24] Krikke H, Bloemhof-Ruwaard J, Van Wassenhove LN. Concurrent product and closed-loop supply chain design with an application to refrigerators. Int J Prod Res 2003:41(16):3689-719.

[25] Alumur SA, Nickel S, Saldanha-da-Gama F, Verter V. Multi-period reverse logistics network design. Eur J Oper Res 2012;220(July (1)):67-78.

[26] Hatefi SM, Jolai F. Robust and reliable forward-reverse logistics network design under demand uncertainty and facility disruptions. Appl Math Model 2013;38:2630-47.

[27] De Rosa V, Gebhard M, Hartmann E, Wollenweber J. Robust sustainable bi-directional logistics network design under uncertainty. Int J Prod Econ 2013:145(September (1)):184-98.

[28] Toso EAV, Alem D. Effective location models for sorting recyclables in public management. Eur J Oper Res 2014;234(May (3)):839-60.

[29] Alimoradi A, Yussuf RM, Zulkifli N. A hybrid model for remanufacturing facility location problem in a closed-loop supply chain. Int J Sustain Eng 2011;4(1):16-23.

[30] Barker T], Zabinsky ZB. A multicriteria decision making model for reverse logistics using analytical hierarchy process. Omega 2011;39(October (5)):558-73.

[31] De Felice F, Petrillo A. Hierarchical model to optimize performance in logistics policies: multi attribute analysis. Proc - Soc Behav Sci October 2012:58:1555-64.

[32] Achillas C, Vlachokostas C, Moussiopoulos N, Banias G. Decision support system for the optimal location of electrical and electronic waste treatment plants: a case study in Greece. Waste Manag 2010;30(May (5)):870-9.

[33] Erol İ, Sencer S, Özmen A, Searcy C. Fuzzy MCDM framework for locating a nuclear power plant in Turkey. Energy Policy April 2014;67:186-97.

[34] Godichaud M. Outils d'aide à la décision pour la sélection des filières de valorisation des produits de la déconstruction des systèmes en fin de vie: application au domaine aéronautique. Toulouse: INP Toulouse; 2009.

[35] Godichaud M, Pérès F, Tchangani A. Disassembly process planning using Bayesian networks. In: Proceedings of Fourh World Congres on Engineering Asset Management (WCEAM). Springer; 2009., ISBN 978-1-84996-002-1 p. 280-7.

[36] Azzone G, Noci G, Manzini R, Welford R, Young CW. Defining environmental performance indicators: an integrated framework. Bus Strategy Environ 1996;5(June (2)):69-80

[37] Saaty T. An eigenvalue allocation model for prioritization and planning. Energy Manag Policy Cent Univ PA 1972:28-31. 
[38] Saaty T. The analytic hierarchy process: planning, priority setting, resource allocation. Texas: Mcgraw-Hill; 1980

[39] Tchangani A, Bouzarour-Amokrane Y, Pérès F. Evaluation model in decision analysis: bipolar approach. Informatica 2012;23(3):461-85.

[40] Saaty T. Decision making with dependence and feedback: the analytic network process; 1996.

[41] Saaty T. The analytic network process, fundamentals of decision making and priority theory; 2001

[42] Saaty T, Özdemir M. The Encyclicon: a dictionary of applications of decision making with dependence and feedback based on the analytic network process. RWS Publications; 2005

[43] Lee AHI, Chen H, Kang H. Multi-criteria decision making on strategic selection of wind farms. Renew Energy 2009;34(January (1)):120-6.

[44] Kainulainen PLT. A statistical approach to assessing interval scale preferences in discrete choice problems. JORS 2009;60:252-8.

[45] Ishizaka A, Labib A. Review of the main developments in the analytic hierarchy process. Expert Syst Appl 2011;38(October (11)):14336-45.

[46] Saaty T. A scaling method for priorities in hierarchical structures.] Math Psychol 1977; 15(June (3)):234-81.

[47] Grabisch M. The application of fuzzy integrals in multicriteria decision making. Eur J Oper Res 1996;89(3):445-56.

[48] Schärlig A. Décider sur plusieurs critères: panorama de l'aide à la décision multicritère. PPUR Presses Polytechniques; 1985.

[49] Marichal J-L. Behavioral analysis of aggregation in multicriteria decision aid. Stud Fuzziness Soft Comput 2000;51:153-78.

[50] Grabisch M, Labreuche C. Fuzzy measures and integrals in MCDA. Multiple criteria decision analysis: state of the art surveys, vol. 78. New York: SpringerVerlag; 2005. p. 563-604.

[51] Grabisch M. Évaluation subjective. HAL; 2006.

[52] Marichal J-L. Aggregation of interacting criteria by means of the discrete Choquet integral. Liege, Belgium: Faculty of Economics, University of Liege; 1999.

[53] Murofushi T, Sugeno M. An interpretation of fuzzy measures and the Choque integral as an integral with respect to a fuzzy measure. Fuzzy Sets Syst January 1989;29:201-27.

[54] Tchangani AP. Bipolar aggregation method for fuzzy nominal classification using weighted cardinal fuzzy measure (wcfm). J Uncertain Syst $2013 ; 7(2): 138-51$.

[55] Tan C. A multi-criteria interval-valued intuitionistic fuzzy group decision making with Choquet integral-based TOPSIS. Expert Syst Appl 2011;38(April (4)):3023-33.

[56] Escobar MT, Moreno-jiménez JM. Aggregation of individual preference structures in Ahp-group decision making. Group Decis Negot 2006;16(October (4)):287-301.
[57] Yang W, Chen Z. New aggregation operators based on the Choquet integral and 2-tuple linguistic information. Expert Syst Appl 2012;39(February (3)): 2662-8.

[58] Marichal J-L (Ph.D. thesis) Aggregation operators for multicriteria decision aid Liege, Belgium: University of Liege; 1998.

[59] Stirling WC. Satisficing games and decision making: with applications to engineering and computer science. Cambridge University Press; 2003.

[60] Tchangani AP. Evaluation model for multiattributes-multiagents decision making: satisficing game approach. Int J Inf Technol Decis Mak 2009;8(1): 73-91.

[61] Bouzarour-Amokrane Y, Tchangani A, Pérès F. Defining and measuring risk and opportunity in BOCR framework for decisions analysis. In: Proceedings of 9th International Conference on Modeling, Optimization and Simulation MOSIM'12. 2012

[62] Bouyssou D, Marchant T, Pirlot M, Perny P, Tsoukias A, Vincke P. Evaluation and decision models - a critical perspective. International series in operations research and management science, vol. 32, 2001 ed. Springer; 2000.

[63] Blackburn JD, Guide VDR, Souza GC, Van Wassenhove LN. Reverse Supply Chains for Commercial Returns. CA Manag Rev 2004;46(Winter (2)):6-22.

[64] Dale RT-L, Rogers S. An examination of reverse logistics practices. J Bus Logist 2011;22(2):129-48

[65] Tchangani AP, Pérès F. BOCR framework for decision analysis. In: Pierre B, Florin Gheorghe F, editors. Proceedings of 12th IFAC Symposium on Large Scale Complex Systems Theory and Applications, vol. 9. 2010. p. 507-13. Part 1, IFAC PapersOnLine.

[66] Bouzarour-Amokrane Y, Tchangani AP, Pérès F. Bipolar approach applied to group decision making problems. Group decision and negotiation. A processoriented view, lecture notes in business information processing, vol. 180 Springer; 2014. p. 144-51.

[67] Bouzarour-Amokrane Y, Tchangani AP, Pérès F. Decision support system for wind farm installation using bipolar analysis. In: Gonzalez-Prida V, Raman A, editors. Promoting sustainable practices through energy engineering and asset management. IGI Global; 2015.

[68] Tchangani AP, Bouzarour Y, Pérès F. Supplier-manufacturer relationship modeling through satisficing games. In: Borangiu T, Dolgui A, Dumitrache I, Florin Gheorghe F, editors. Proceedings of 14th IFAC Symposium on Information Control Problems in Manufacturing, INCOM 2012, vol. 14. Bucharest, Romania: Elsevier; 2012. p. 540-6. Part\# 1, ISBN: 978-3-902661-98-2, May 23-25, IFAC PapersOnLine.

[69] Bouzarour Y, Tchangani AP, Pérès F. Evaluation process in end-of-life systems management using BOCR analysis. In: Bakhtadze N, Chernyshov K, Dolgui A, Lototsky V, editors. Proceedings of 7th IFAC Conference on Manufacturing Modelling, Management, and Control. 2013. p. 105-10. IFAC-PapersOnline. 